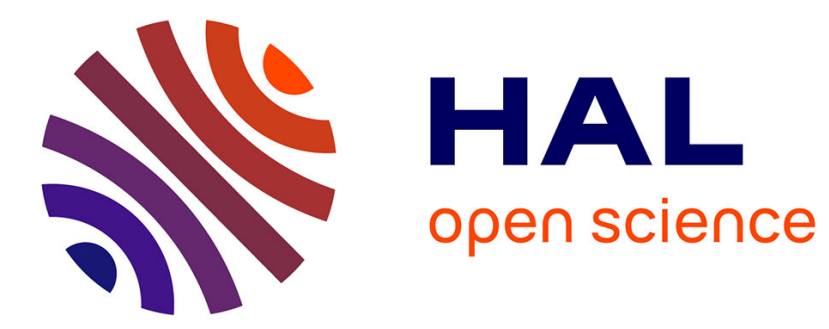

\title{
Aggregation in isomeric imides: analysis of the weak interactions in six $\mathrm{N}$-(benzoyl)-N-(2-pyridyl)benzamides
}

Pavle Mocilac, Mark Farrell, Alan Lough, Christian Jelsch, John Gallagher

\section{To cite this version:}

Pavle Mocilac, Mark Farrell, Alan Lough, Christian Jelsch, John Gallagher. Aggregation in isomeric imides: analysis of the weak interactions in six N-(benzoyl)-N-(2-pyridyl)benzamides. Structural Chemistry, 2018, 29 (4), pp.1153-1164. 10.1007/s11224-018-1101-9 . hal-02358749

\author{
HAL Id: hal-02358749 \\ https://hal.science/hal-02358749
}

Submitted on 12 Nov 2019

HAL is a multi-disciplinary open access archive for the deposit and dissemination of scientific research documents, whether they are published or not. The documents may come from teaching and research institutions in France or abroad, or from public or private research centers.
L'archive ouverte pluridisciplinaire HAL, est destinée au dépôt et à la diffusion de documents scientifiques de niveau recherche, publiés ou non, émanant des établissements d'enseignement et de recherche français ou étrangers, des laboratoires publics ou privés. 


\title{
Aggregation in isomeric imides: analysis of the weak interactions in six $\mathrm{N}$-(benzoyl)- $\mathrm{N}$-(2-pyridyl)benzamides.
}

\author{
Pavle Mocilac, ${ }^{a}$ Mark Farrell, ${ }^{a}$ Alan J. Lough, ${ }^{b}$ Christian Jelsch ${ }^{c^{*}}$ and John F. Gallagher ${ }^{a, c^{*}}$ \\ ${ }^{a}$ School of Chemical Sciences, Dublin City University, Dublin 9, Ireland, \\ ${ }^{b}$ Department of Chemistry, 80 St. George Street, University of Toronto, Toronto, M5S 3H6, \\ ON, Canada \\ ${ }^{C} C R M 2, C N R S$, Faculté des Sciences et Technologies, Université de Lorraine, BP, 70239, \\ Boulevard des Aiguellettes, 54506 Vandoeuvre-dès-Nancy, France
}

* Corresponding author: Dr. John F. Gallagher

E-mail: john.gallagher@dcu.ie

Telephone: +353-1-7005114

Fax: $\quad+353-1-7005503$

\begin{abstract}
Crystal structures of 4-Chloro- $N$-(4-chlorobenzoyl)- $N$-(2-pyridyl)benzamide (I) Clpod, 3Chloro- $N$-(3-chlorobenzoyl)- $N$-(2-pyridyl)benzamide (II) Clmod and 2-Chloro- $N$-(2chlorobenzoyl)- $N$-(2-pyridyl)benzamide (III) Clood together with three methylated analogues Mpod, Mmod, Mood are presented herein. The Clxod acyclic imides are produced from reacting the 4-/3-/2-chlorobenzoyl chlorides (Clx) with 2-aminopyridine (o), respectively, together with their benzamide analogues Clxo; the Mxod/Mxo triad are produced similarly and in good yield. The five Clxod, Mpod and Mmod structures adopt the open transoid conformations as expected, but Mood crystallises with cisoid oriented benzoyl groups, and this conformation was unexpected, though not unknown. Halogen bonding contacts and weak hydrogen bonding $\mathrm{C}-\mathrm{H} \cdots \mathrm{N} / \mathrm{O} / \pi$ contacts are noted in the structures lacking strong hydrogen bonding donor atoms/groups but possessing a variety of strong and weaker acceptor atoms/groups. For Clxod, contact studies show that both hydrogen and carbon account for a high percentage of elements (70-75\%) on the molecular surface and being the most abundant have $\mathrm{C} \cdots \mathrm{H}$ forming $26-30 \%$ of the contacts. Contact enrichment ratios are an indicator of the likelihood of chemical species to form intermolecular interactions with themselves and other species. The $\mathrm{C}-\mathrm{H} \cdots \mathrm{N}$ and $\mathrm{C}-\mathrm{H} \cdots \mathrm{O}$ are the most enriched (with $E_{\mathrm{HN}}>2.15$ ), indicating that these weak hydrogen bonds are the driving force in the Clxod crystal packing formation. For Mxod, the $\mathrm{C} \cdots \mathrm{H}$ contact type at 40$52 \%$ is the most abundant contact type and $\mathrm{C}-\mathrm{H} \cdots \mathrm{O}$ and $\mathrm{C}-\mathrm{H} \cdots \mathrm{N}$ weak hydrogen bonds dominate with enrichment values in the 1.48-1.78 range. In Mxod N/O $\cdots \mathrm{N} / \mathrm{O}$ contacts are effectively absent, except for Mpod $(0.2 \%, \mathrm{~N} \cdots \mathrm{N}$ contacts) and both $\mathrm{H} \cdots \mathrm{H}$ and $\mathrm{C} \cdots \mathrm{C}$ nonpolar contacts are moderately impoverished while the $\mathrm{C} \cdots \mathrm{H}$ interactions are slightly enriched ( $E=1.1-1.21$ ).
\end{abstract}

Keywords: Chlorine; Contact Enrichment ratio; Crystal structure; Imide; Methyl; Weak interactions. 


\section{Introduction}

The reaction chemistry of open-chain imides has developed from condensation reactions of benzoyl chlorides with 2-aminopyridines and pyrimidines, whereby a mixture of the (1:1) benzamide and (2:1) acyclic imides are formed, the relative amount (yield) of each depending on the nature of the starting materials and reaction conditions [1,2]. The dibenzoylation reaction is well known and first described by Marckwald in 1894 and subsequently developed [1,2]. More recently, Gale and Evans reported tetrameric imide macrocycles in low yield from the reaction of isophthaloyl dichloride with tetra- and pentafluoroaniline [3]. Given that the acyclic imide structure sterically fits a part ( 3/8) of the tetramer macrocyclic skeleton [3] when centred about the imide hinge linkage, we developed acyclic imides based on 2-aminopyridines [4,5] and subsequently synthesised the corresponding cyclic triimides and tetraimides [6-8]. These trezimide (trimer) and tennimide (tetramer) macrocycles are isolated from the reaction of isophthaloyl dichloride with 2aminopyridines and 2-aminopyrimidines [6-8]. Herein, we report six imides as three chlorinated imides Clpod, Clmod, Clood (I)-(III) and their methylated analogues Mxod (IV)(VI) (Figure 1) to further expand on structural knowledge of acyclic imides as macrocyclic precursors and building blocks from the viewpoint of developing macrocyclic and oligomer/polymer imide chemistry. The importance of rational design in the synthesis of macrocycles with an emphasis on molecular knots has been recently discussed [9].

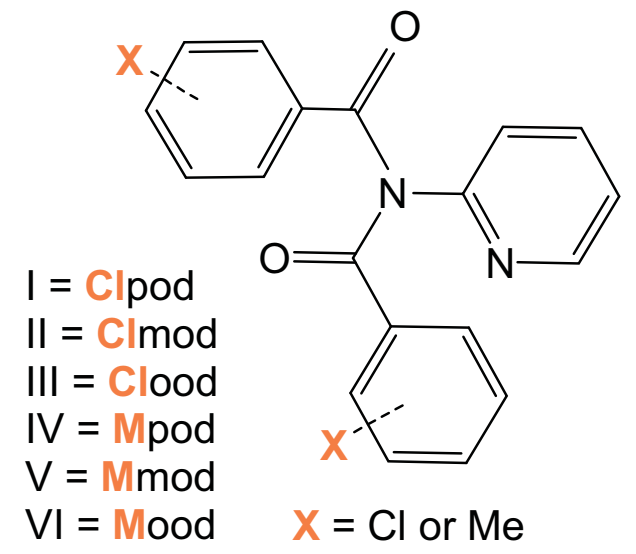

Figure 1: Schematic diagram of the six Clxod and Mxod isomers.

\section{Experimental section}

\subsection{Materials and equipment}

All chemicals, materials, vendors, spectroscopic and crystallographic methods as well as computational equipment are as described previously [6-8]. Chemicals and silica (Davisil) were purchased from Sigma Aldrich, TLC alumina and silica plates from Fluka. Melting points were analyzed using a Stuart Scientific SMP40 automated melting point apparatus. IR spectroscopy was performed on a Perkin Elmer Spectrum GX FTIR spectrometer using a $\mathrm{KBr}$ disk and/or thin layer method: bands are stated in $\mathrm{cm}^{-1}$. NMR spectroscopy was performed on a Bruker BioSpin UltraShield NMR spectrometer $(293 \pm 1 \mathrm{~K})$, at 400 or $600 \mathrm{MHz}$ for the ${ }^{1} \mathrm{H}$, 100.62 MHz for the ${ }^{13} \mathrm{C}$ resonance. The ${ }^{1} \mathrm{H},{ }^{13} \mathrm{C}$ NMR spectra were recorded in $\mathrm{CDCl}_{3}$ or DMSO- $d^{6}$ and the chemical shift values $(\delta)$ are in ppm, referenced to TMS and coupling constants $(J)$ are quoted in $\mathrm{Hz}$. Spectroscopic data are provided in the ESI. 


\subsection{Synthesis, Characterisation and Crystallization:}

The three Clpod to Clood isomers or (I)-(III) were synthesised by the condensation reaction of the corresponding 4-/3-/2-chlorobenzoyl chloride (Clx) with 2-aminopyridine (o) by standard condensation reaction protocols $[10,4,5]$. The Mxod triad were synthesised using similar methodologies. Standard chromatographic separation of the six Clxod, Mxod imides from their corresponding Clxo, Mxo benzamides were performed to obtain pure, clean products. All three Clxod crystal samples were grown from ethyl acetate solutions, whereas crystals of Mpod (ethyl acetate), Mmod (cyclohexane) and Mood (cyclohexane) were obtained from slow evaporation of their solutions at room temperature to yield colourless blocks suitable for single crystal X-ray analysis.

\section{Synthesis and characterisation data:}

Clpod (yield = 23\%; m.p. = 171.5-175.5 ${ }^{\circ} \mathrm{C}$ ). IR (thin layer): 3058 (w), 2921 (w), 2356 (w), 1792 $(\mathrm{w} / \mathrm{m}), 1693(\mathrm{~s}), 1589(\mathrm{~s}), 1485(\mathrm{~m}), 1436(\mathrm{~s}), 1397(\mathrm{~m}), 1288(\mathrm{~s}), 1244(\mathrm{~s}), 1090(\mathrm{~s}), 1014(\mathrm{~s})$, $866(\mathrm{~s}), 751$ (s). ${ }^{1} \mathrm{H}$ NMR $\left(\mathrm{CDCl}_{3}\right)$ 8: $7.13(1 \mathrm{H}), 7.20(1 \mathrm{H}), 7.27(4 \mathrm{H}), 7.63(4 \mathrm{H}), 7.68(1 \mathrm{H}), 8.33$ (1H).

Clmod (yield = 26\%; m.p. = 111-115 ${ }^{\circ} \mathrm{C}$ ). IR (thin layer): 3065 (w), 3018 (w),1795 (s), 1695 (s), $1590(\mathrm{~s}), 1569(\mathrm{~s}), 1469(\mathrm{~s}), 1416(\mathrm{~m}), 1290(\mathrm{~s}), 1233(\mathrm{~s}), 1143(\mathrm{~m}), 1044(\mathrm{~m}), 886(\mathrm{w}) .{ }^{1} \mathrm{H}$ $\operatorname{NMR}\left(\mathrm{CDCl}_{3}\right) \delta 7.23(1 \mathrm{H}, \mathrm{q}), 7.30(3 \mathrm{H}, \mathrm{m}), 7.47(1 \mathrm{H}, \mathrm{d}), 7.52(1 \mathrm{H}, \mathrm{t}), 7.63(2 \mathrm{H}, \mathrm{d}), 7.78(3 \mathrm{H}, \mathrm{m})$, $8.42(1 \mathrm{H}, \mathrm{d})$.

Clood (yield $=25 \%$; m.p. $=113.7-117.4^{\circ} \mathrm{C}$ ). IR (thin layer): $3063(\mathrm{~m}), 3019(\mathrm{~m}), 2362(\mathrm{w})$, $1699(\mathrm{~s}), 1667(\mathrm{~s}), 1468(\mathrm{~s}), 1436(\mathrm{~s}), 1244(\mathrm{~s}), 1145(\mathrm{~s}), 1090(\mathrm{~m}), 1052(\mathrm{~s}), 997(\mathrm{~m}), 855(\mathrm{~m})$, $751(\mathrm{~s}) .{ }^{1} \mathrm{H} N M R\left(\mathrm{CDCl}_{3}\right) \delta 7.17(7 \mathrm{H}, \mathrm{m}), 7.41(1 \mathrm{H}, \mathrm{d}), 7.49(2 \mathrm{H}, \mathrm{d}), 7.68(1 \mathrm{H}, \mathrm{t}), 8.37(1 \mathrm{H}, \mathrm{d})$.

Mpod $\left(0.50\right.$ g; yield $=38 \% ;$ m.p. $\left.=165.3-165.9^{\circ} \mathrm{C}\right)$. IR (thin layer): $1686(\mathrm{~s}), 1609(\mathrm{~m}), 1588$ (m), $1572(\mathrm{w}) ; \mathrm{IR}\left(\mathrm{KBr}\right.$ disc): 1703 (s), 1681 (s), $1605(\mathrm{~s}), 1589(\mathrm{~m}), 1572(\mathrm{~m}) ;{ }^{1} \mathrm{H} \mathrm{NMR}\left(\mathrm{CDCl}_{3}\right)$ d $2.27(6 \mathrm{H}, \mathrm{s}),, 7.07(4 \mathrm{H}, \mathrm{d}), 7.19(1 \mathrm{H}, \mathrm{d}), 7.60(4 \mathrm{H}, \mathrm{dd}), 7.63(1 \mathrm{H}, \mathrm{td}), 8.32(1 \mathrm{H}, \mathrm{ddd}) ;{ }^{1} \mathrm{H} N M R$ $\left(\right.$ DMSO- $\left.d^{6}\right) \delta 2.32,(6 \mathrm{H}, \mathrm{s}), 7.24(4 \mathrm{H}, \mathrm{d}), 7.27(1 \mathrm{H}, \mathrm{ddd}), 7.53(1 \mathrm{H}, \mathrm{dt}), 7.64(4 \mathrm{H}, \mathrm{dd}), 7.89(1 \mathrm{H}$, td), $8.29(1 \mathrm{H}, \mathrm{ddd}) ;{ }^{13} \mathrm{C}$ NMR (DMSO-d $\left.d^{6}\right) \delta 21.04,122.19,122.40,129.12,129.23,131.57$, $138.67,143.03,148.71,153.53,172.62$.

Mmod (0.50 g; yield = 38\%; m.p. = $\left.148.5-150.5^{\circ} \mathrm{C}\right)$ IR (thin layer): 1691 (s), $1605(\mathrm{w}), 1588$ (s), $1572(\mathrm{w}) ; \mathrm{IR}$ ( $\mathrm{KBr}$ disc): 1697 (s), $1684(\mathrm{~s}), 1608(\mathrm{w}), 1590(\mathrm{~m}) ;{ }^{1} \mathrm{H} \mathrm{NMR}\left(\mathrm{CDCl}_{3}\right) \delta 2.25(6 \mathrm{H}$, s), $7.08(1 \mathrm{H}, \mathrm{ddd}), 7.13(2 \mathrm{H}, \mathrm{t}), 7.18(2 \mathrm{H}, \mathrm{d}), 7.20(1 \mathrm{H}, \mathrm{dt}), 7.46(2 \mathrm{H}, \mathrm{d}), 7.54(2 \mathrm{H}, \mathrm{s}), 7.65(1 \mathrm{H}$, $\mathrm{td}), 8.33(1 \mathrm{H}, \mathrm{ddd}) ;{ }^{1} \mathrm{H}$ NMR (DMSO-d $\left.d^{6}\right) \mathrm{d} 2.31(6 \mathrm{H}, \mathrm{s}),, 7.29(1 \mathrm{H}, \mathrm{ddd}), 7.32(2 \mathrm{H}, \mathrm{t}), 7.37(2 \mathrm{H}$, d), $7.55(2 \mathrm{H}, \mathrm{d}), 7.58(1 \mathrm{H}, \mathrm{dt}), 7.59(2 \mathrm{H}, \mathrm{s}), 7.92(1 \mathrm{H}, \mathrm{td}), 8.33(1 \mathrm{H}, \mathrm{ddd}) ;{ }^{13} \mathrm{C} N M R$ (DMSO- $\left.d^{6}\right)$ $\delta$ 20.72, 122.35, 122.55, 126.08, 128.48, 129.40, 133.22, 134.40, 138.12, 138.70, 148.75, $153.39,172.82$.

Mood $\left(0.50\right.$ g; yield = 38\%; m.p. = 104.8-105.5 $\left.{ }^{\circ} \mathrm{C}\right)$ IR (thin layer): $1698(\mathrm{~s}), 1672(\mathrm{~s}), 1600(\mathrm{~s})$, 1572 (m); IR (KBr disc): 1714 (s), 1673 (s), $1588(\mathrm{~s}) ;{ }^{1} \mathrm{H}$ NMR $\left(\mathrm{CDCl}_{3}\right) \delta 2.34(6 \mathrm{H}, \mathrm{s}), 7.02(4 \mathrm{H}$, m), $7.11(1 \mathrm{H}, \mathrm{ddd}), 7.14(2 \mathrm{H}, \mathrm{td}), 7.27(1 \mathrm{H}, \mathrm{dt}), 7.49(2 \mathrm{H}, \mathrm{dd}), 7.67(1 \mathrm{H}, \mathrm{td}), 8.39\left(1 \mathrm{H}, \mathrm{ddd},{ }^{3} \mathrm{~J}=\right.$ $\left.4.9,{ }^{4} \mathrm{~J}=1.9,{ }^{5} \mathrm{~J}=0.8, \mathrm{H} 25\right) ;{ }^{1} \mathrm{H}$ NMR (DMSO- $\left.d^{6}\right) \mathrm{d} 2.35(6 \mathrm{H}, \mathrm{s}), 7.19(4 \mathrm{H}, \mathrm{m}), 7.29(2 \mathrm{H}, \mathrm{td}), 7.30$ $(1 \mathrm{H}, \mathrm{dd}), 7.61(1 \mathrm{H}, \mathrm{dt}), 7.66(2 \mathrm{H}, \mathrm{d}), 7.89(1 \mathrm{H}, \mathrm{td}), 8.39(1 \mathrm{H}, \mathrm{ddd}) ;{ }^{13} \mathrm{C} N M R$ (DMSO- $\left.d^{6}\right) \delta$ $19.37,123.03,125.53,127.50,130.82,130.88,135.29,137.29,138.61,140.03,149.03$, $152.63,172.42$.

\subsection{Crystallographic details}

Crystal data, data collection and structure refinement details for the six Clxod and Mxod crystal structures are summarized in Table 1. For Clxod the $\mathrm{H}$ atoms attached to $\mathrm{C}$ atoms 
were constrained and treated as riding atoms using the SHELXL14 [11] defaults at 294(2) K with the $\mathrm{C}-\mathrm{H}=0.93 \AA$ (aromatic) and $\mathrm{U}_{\text {iso }}(\mathrm{H})=1.2 \mathrm{U}_{\text {eq }}(\mathrm{C})$ (aromatic). For Mxod, a similar treatment using the SHELXL14 [11] defaults at 150(1) K had C-H $=0.95 \AA, \mathrm{U}_{\text {iso }}(H)=1.2 \mathrm{U}_{\text {eq }}(\mathrm{C})$ for aromatic $\mathrm{C}-\mathrm{H}$ and $\mathrm{C}-\mathrm{H}=0.98 \AA, \mathrm{U}_{\text {iso }}(\mathrm{H})=1.5 \mathrm{U}_{\text {eq }}(\mathrm{C})$ for the two $\mathrm{CH}_{3} \mathrm{H}$ atoms.

In summary: for the Clxod isomers: Molecular formula: $\mathrm{C}_{19} \mathrm{H}_{12} \mathrm{Cl}_{2} \mathrm{~N}_{2} \mathrm{O}_{2}, M_{\mathrm{r}}=371.21$. Experiments were performed at 294(1) K with Mo Ka radiation using a Xcalibur, Sapphire3, Gemini Ultra diffractometer and an analytical absorption correction (ABSFAC) [12]. For the Mxod isomers: Molecular formula: $\mathrm{C}_{21} \mathrm{H}_{18} \mathrm{~N}_{2} \mathrm{O}_{2}, \mathrm{Mr}=330.37$. Experiments were undertaken at $150(1) \mathrm{K}$ with Mo $K \alpha$ radiation using a Nonius $\kappa$-CCD diffractometer. Refinement was standard for Clxod, Mpod and Mmod but the o-tolyl ring disorder in Mood required additional treatment and refinement using SHELXL14 [11] (Figures 2-7).

\subsection{Molecular disorder in the Mood structure (VI)}

There is no molecular disorder present in any of the Clxod molecular structures (Figure 2). In Mpod (IV) rotational disorder is present in one of the $\mathrm{CH}_{3}$ groups (methyl group C37), while no disorder is present in Mmod (V). However, in Mood (VI), there is aromatic group disorder in one of the o-tolyl groups (C31A/C31B) with the major site having $0.905(4)$ site occupancy (Figure 6; right) and rotated by $180^{\circ}$ relative to the minor component with 0.095(4) site occupancy. The tolyl group disorder was observed in the final stages of refinement with the $R$-factor $=0.07$ [11]. The residual electron density values at this stage of refinement were $+0.55 /-0.33$ e. $\AA^{-3}$ and the residual peaks located beside one of the $o$-tolyl groups. The analysis provided an indication of a minor disordered ring component at C31. A disorder model with $10 \%$ site occupancy for the minor component was introduced (estimated from residual electron density) and the Mood structure was refined to a final $R$ factor of 0.06 with residual electron density values of $+0.24 /-0.24$ e. $\AA^{-3}$ [11]. Both major:minor components essentially occupy the same volume element and the group disorder does not affect the remainder of the molecular conformation which adopts a cisoid-arrangement with respect to the o-tolyl rings. There is no evidence of carbonyl group disorder i.e. a 9.5\% occupancy $\mathrm{O}$ atom oriented to ensure that both major and minor sites are related anti to the ortho-methyl groups on the $o$-tolyl ring. In packing terms, the Mxod unit cell volume differences are only $\sim 3 \%$, with Mood $=1661.47(15) \AA^{3}$ and $\mathbf{M m o d}=$ 1713.26(9) $\AA^{3}$. The KPI values are $(\mathrm{Mpod})=70.6,(\mathrm{Mmod})=68.7$ and $(\mathrm{Mood})=70.7$ (before consideration of the molecular disorder) [11]. 
Table 1: Selected crystallographic data for the Clxod and Mxod compounds ${ }^{\dagger}$

\begin{tabular}{|c|c|c|c|c|c|c|}
\hline & Clpod & Clmod & Clood & Mpod & Mmod & Mood \\
\hline \multicolumn{7}{|l|}{ Crystal data } \\
\hline $\begin{array}{l}\text { Crystal system, } \\
\text { space group }\end{array}$ & $\begin{array}{l}\text { Monoclinic, } \\
P 2_{1} / c\end{array}$ & Triclinic, $P \overline{\mathbf{1}}$ & Triclinic, $P \overline{\mathbf{1}}$ & $\begin{array}{l}\text { Monoclinic, } \\
P 2_{1} / c\end{array}$ & $\begin{array}{l}\text { Monoclinic, } \\
P 2_{1} / c\end{array}$ & $\begin{array}{l}\text { Monoclinic, } \\
P 2_{1} / n\end{array}$ \\
\hline$a, b, c(\AA)$ & \begin{tabular}{|l}
$5.50192(13)$, \\
$33.6477(8)$, \\
$9.3238(2)$
\end{tabular} & \begin{tabular}{|l|}
$5.7482(4)$, \\
$8.3059(4)$, \\
$18.6669(10)$ \\
\end{tabular} & $\begin{array}{l}\text { 7.8395(4), } \\
9.3231(5) \\
12.3187(7) \\
\end{array}$ & \begin{tabular}{|l|}
$8.3673(2)$, \\
$17.2287(9)$, \\
$11.7386(5)$ \\
\end{tabular} & \begin{tabular}{|l}
$10.9339(2)$, \\
$15.2963(5)$, \\
$10.3382(4)$
\end{tabular} & $\begin{array}{l}12.9419(6), \\
8.3155(5), \\
15.7840(7)\end{array}$ \\
\hline$\alpha, b, v\left(^{\circ}\right)$ & $\begin{array}{l}90 \\
90.155(2), \\
90\end{array}$ & \begin{tabular}{|l|}
$101.388(4)$, \\
$90.265(5)$, \\
$105.330(5)$
\end{tabular} & $\begin{array}{l}89.608(5), \\
71.446(5), \\
87.399(4)\end{array}$ & $\begin{array}{l}90, \\
94.465(3), \\
90\end{array}$ & $\begin{array}{l}90, \\
97.747(2), \\
90\end{array}$ & \begin{tabular}{|l}
90, \\
$102.010(3)$, \\
90,
\end{tabular} \\
\hline$V\left(\AA^{3}\right)$ & $1726.08(7)$ & $841.08(9)$ & $852.65(8)$ & $1687.07(12)$ & $1713.26(9)$ & $1661.47(15$ \\
\hline$Z$ & 4 & 2 & 2 & 4 & 4 & 4 \\
\hline$\mu\left(\mathrm{mm}^{-1}\right)$ & 0.39 & 0.40 & 0.40 & 0.09 & 0.08 & 0.09 \\
\hline Crystal size $(\mathrm{mm})$ & $\begin{array}{l}0.59 \times 0.09 \times \\
0.06\end{array}$ & $\begin{array}{l}0.35 \times 0.25 \times \\
0.25\end{array}$ & $\begin{array}{l}0.22 \times 0.22 \times \\
0.09\end{array}$ & $\begin{array}{l}0.35 \times 0.30 \\
\times 0.26 \\
\end{array}$ & $\begin{array}{l}0.40 \times 0.30 \times \\
0.20\end{array}$ & $\begin{array}{l}0.17 \times 0.13 \\
\times 0.10 \\
\end{array}$ \\
\hline \multicolumn{7}{|l|}{ Data collection } \\
\hline$T_{\min ,}, T_{\max }$ & $0.89,1.00$ & $0.94,1.00$ & $0.934,0.977$ & $0.810,0.981$ & $0.967,0.984$ & $0.986,0.992$ \\
\hline \begin{tabular}{|l|} 
Measured, \\
independent and \\
observed $[I>2 \sigma$ \\
$(I)]$ reflections \\
\end{tabular} & $\begin{array}{l}12110,3658, \\
2247\end{array}$ & $\begin{array}{l}5996,3598, \\
3012\end{array}$ & $\begin{array}{l}6154,3666, \\
2879\end{array}$ & $\begin{array}{l}12779, \\
3856,2587\end{array}$ & $\begin{array}{l}\text { 15391, 3897, } \\
2896\end{array}$ & $\begin{array}{l}10391, \\
3779,1802\end{array}$ \\
\hline$R_{\text {int }}$ & 0.033 & 0.012 & 0.011 & 0.049 & 0.048 & 0.073 \\
\hline $\sin \theta_{\max } / \lambda\left(\AA^{-1}\right)$ & 0.640 & 0.648 & 0.646 & 0.649 & 0.650 & 0.651 \\
\hline \multicolumn{7}{|l|}{ Refinement } \\
\hline $\begin{array}{l}R\left[F^{2}>2 \sigma\left(F^{2}\right)\right], \\
w R\left(F^{2}\right), S\end{array}$ & $\begin{array}{l}0.038,0.088, \\
0.89\end{array}$ & $\begin{array}{l}0.033,0.086, \\
1.05\end{array}$ & $\begin{array}{l}0.035,0.097, \\
1.09\end{array}$ & $\begin{array}{l}0.048, \\
0.135,1.04\end{array}$ & $\begin{array}{l}0.047,0.130 \\
1.04\end{array}$ & $\begin{array}{l}0.060, \\
0.173,1.01\end{array}$ \\
\hline $\begin{array}{l}\text { Reflections, } \\
\text { parameters }\end{array}$ & 3658,226 & 3598,226 & 3666,226 & 3856,229 & 3897,229 & 3779,241 \\
\hline $\begin{array}{l}\Delta \rho_{\max ,}, \Delta \rho_{\min } \\
\left(\mathrm{e} . \AA^{-3}\right)\end{array}$ & $0.19,-0.24$ & $0.28,-0.30$ & $0.25,-0.35$ & $0.25,-0.23$ & $0.21,-0.24$ & $0.24,-0.24$ \\
\hline
\end{tabular}

Computer programs ${ }^{\dagger}$ : CrysAlisPRO[13], SHELXS14/6[11], SHELXL14[11] and SORTX[14], PLATON[15], SHELXL14/6[11]. 
Table 2. Selected hydrogen-bond parameters for Clxod and Mxod.

\begin{tabular}{|c|c|c|c|}
\hline$D-\mathrm{H} \cdots A$ & $H \cdots A(\AA)$ & $D \cdots A(\AA)$ & $D-\mathrm{H} \cdots A\left({ }^{\circ}\right)$ \\
\hline \multicolumn{4}{|l|}{ (a) Clpod } \\
\hline $\mathrm{C} 12-\mathrm{H} 12 \cdots \mathrm{O}^{i}$ & 2.54 & $3.300(2)$ & 139 \\
\hline $\mathrm{C} 24-\mathrm{H} 24 \cdots \mathrm{O} 2^{\mathrm{ii}}$ & 2.54 & $3.405(2)$ & 155 \\
\hline $\mathrm{C} 36-\mathrm{H} 36 \cdots \mathrm{N} 22^{\mathrm{iii}}$ & 2.56 & $3.310(2)$ & 138 \\
\hline $\mathrm{C} 25-\mathrm{H} 25 \cdots \mathrm{Cg} 1^{\mathrm{ii}}$ & 2.88 & $3.760(3)$ & 158 \\
\hline \multicolumn{4}{|l|}{ (b) Clmod } \\
\hline $\mathrm{C} 24-\mathrm{H} 24 \cdots \mathrm{O} 2^{\mathrm{iv}}$ & 2.62 & $3.1714(18)$ & 119 \\
\hline $\mathrm{C} 25-\mathrm{H} 25 \cdots \mathrm{O} 2^{\mathrm{iv}}$ & 2.55 & $3.1409(17)$ & 122 \\
\hline $\mathrm{C} 12-\mathrm{H} 12 \cdots \mathrm{Cl} 13^{v}$ & 2.84 & $3.7552(15)$ & 169 \\
\hline \multicolumn{4}{|l|}{ (c) Clood } \\
\hline $\mathrm{C} 13-\mathrm{H} 13 \cdots \mathrm{O} 1^{\mathrm{iii}}$ & 2.54 & $3.452(2)$ & 168 \\
\hline $\mathrm{C} 14-\mathrm{H} 14 \cdots \mathrm{O}^{\mathrm{vi}}$ & 2.59 & $3.505(2)$ & 167 \\
\hline $\mathrm{C} 16-\mathrm{H} 16 \cdots \mathrm{O} 2^{\mathrm{vii}}$ & 2.50 & $3.380(2)$ & 159 \\
\hline $\mathrm{C} 26-\mathrm{H} 26 \cdots \mathrm{O} 1^{\mathrm{viii}}$ & 2.59 & $3.443(2)$ & 153 \\
\hline \multicolumn{4}{|l|}{ (e) Mpod } \\
\hline $\mathrm{C} 17-\mathrm{H} 17 \mathrm{C} \cdots \mathrm{O} 1^{\mathrm{iii}}$ & 2.46 & $3.317(2)$ & 146 \\
\hline $\mathrm{C} 36-\mathrm{H} 36 \cdots \mathrm{N} 1$ & 2.56 & $2.883(2)$ & 100 \\
\hline $\mathrm{C} 24-\mathrm{H} 24 \cdots \mathrm{Cg}^{\text {xiv }}$ & 2.63 & $3.5082(18)$ & 154 \\
\hline $\mathrm{C} 33-\mathrm{H} 33 \cdots \mathrm{Cg} 1^{\text {ix }}$ & 2.80 & $3.6828(18)$ & 154 \\
\hline \multicolumn{4}{|l|}{ (f) Mmod } \\
\hline $\mathrm{C} 16-\mathrm{H} 16 \cdots \mathrm{O} 2^{\mathrm{ix}}$ & 2.57 & $3.4505(18)$ & 154 \\
\hline $\mathrm{C} 36-\mathrm{H} 36 \cdots \mathrm{O} 2^{\mathrm{ix}}$ & 2.46 & $3.3913(17)$ & 166 \\
\hline $\mathrm{C} 25-\mathrm{H} 25 \cdots \mathrm{Cg} 1^{\text {ix }}$ & 2.88 & $3.7056(16)$ & 146 \\
\hline \multicolumn{4}{|l|}{ (g) Mood } \\
\hline $\mathrm{C} 13-\mathrm{H} 13 \cdots \mathrm{N} 22^{\mathrm{x}}$ & 2.61 & $3.342(3)$ & 134 \\
\hline $\mathrm{C} 16-\mathrm{H} 16 \cdots \mathrm{O} 2^{\mathrm{vii}}$ & 2.54 & $3.408(3)$ & 152 \\
\hline C17-H17A $\cdots \mathrm{O} 1$ & 2.39 & $3.113(3)$ & 130 \\
\hline C37A-H37C $\cdots O 1^{x i}$ & 2.60 & $3.317(3)$ & 131 \\
\hline
\end{tabular}

Footnote: symmetry codes: (i) -1-x, -y, -z; (ii) $x, y, 1+z$; (iii) 1+x, $y, z$; (iv) 1+x, 1+y, z; (v) - $x, 1-y,-z$; (vi) 2-x, 1-y, -z; (vii) $1-x, 1-y,-z$; (viii) $1-x,-y,-z$; (ix) $x, 1 / 2-y, z-1 / 2$; (x) x-1/2, -y+3/2, z-1/2; (xi) 1/2-x, 1/2+y, 1/2-z.

Symmetry codes used for the halogen $\mathrm{Cl} \cdots \mathrm{Cl} / \mathrm{Cl} \cdots \mathrm{O}$ contacts: (xii) 1-x,-y,1-z; (xiii) -x, -y, -z.

Symmetry codes used for $\mathrm{C}-\mathrm{H} \cdots \pi$ (arene) are (ii), (ix), (xiv) $-1+\mathrm{x}, \mathrm{y}, \mathrm{z}$.

$\mathrm{Cg} 1$ is the aromatic ring centroid of $[\mathrm{C} 11, \ldots, \mathrm{C} 16], \mathrm{Cg} 3$ is the ring centroid of $[\mathrm{C} 31, \ldots, \mathrm{C} 36]$. 


\section{Results and discussion}

\subsection{Molecular features - Clxod structures}

The three Clxod molecular structures have similar bond lengths and angles (Figure 2). For example, the six C-Cl bond lengths are in a narrow range from $1.7286(18)$ to $1.7437(14) \AA$ and the central imide angles do not differ by more than $2^{\circ}$. The three aromatic inter-planar angles are within $12^{\circ}$ for the Clpod, Clmod pair and within $6^{\circ}$ in Clood. The imide torsion angles show that the Clxod structures have similar geometries with C11-C1-N1-C21 153.72 $(15)^{\circ}$ for Clpod, $-163.07(12)^{\circ}$ for Clmod and $-161.51(13)^{\circ}$ for Clood, whereas C31-C2$\mathrm{N} 1-\mathrm{C} 21$ is $44.6(2)^{\circ},-45.46(17)^{\circ}$ and $23.80(19)^{\circ}$, respectively. Differences are mainly due to the orientation of the pendant (hetero)aromatic rings attached to the central $(\mathrm{OC})_{2} \mathrm{~N}$ imide linker in the Clxod structures. The carbonyl torsion angles defining the imide hinge as $\mathrm{O} 1=\mathrm{C} 1 \cdots \mathrm{C} 2=\mathrm{O} 2$ are $98.2(2)^{\circ}, 105.8(2)^{\circ}$ and $127.6(2)^{\circ}$ with the latter being forced on steric grounds (ortho- $\mathrm{Cl}$ atom, Figure 2 ) from the expected ranges for hinge torsion angles [6-8].

Of further interest is that all three Clxod compounds could potentially be used as asymmetric tridentate ligands for reaction with metal complexes as these ligands contain a pyridine $\mathrm{N}$-donor group together with two weaker $\mathrm{C}=\mathrm{O}$ donor ligand groups. This tridentate [N/O/O] donor set is oriented from the central pyramidal $s p^{3}$ imide $N$ scaffold atom. The interatomic distances between the three potential $\mathrm{N} / \mathrm{O} / \mathrm{O}$ donor atoms is in the range

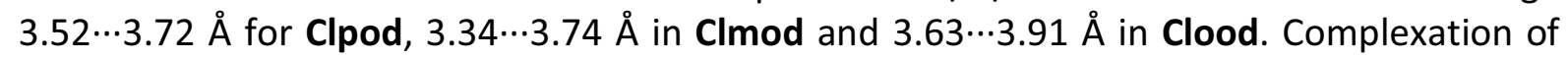
the $[\mathrm{N} / \mathrm{O} / \mathrm{O}]$ donor set to a metal centre in a tridentate fashion, would thus generate 6membered metallorings.

\subsection{Supramolecular features - Clxod structures}

The three Clxod isomers are suitable candidates for the study of weaker intermolecular interactions as they lack strong hydrogen bond donor atoms such as $\mathrm{O}-\mathrm{H}$ or $\mathrm{N}-\mathrm{H}$ (Figures 2, 3) [16]. Therefore, having potentially strong acceptor atoms/groups such as $(\mathrm{O}=\mathrm{C})$, pyridine$N$ as well as weak acceptors (aromatic rings, $\mathrm{N}, \mathrm{Cl}$ ), but only relatively weak hydrogen bonding donors $\mathrm{C}-\mathrm{H}$, aggregation is likely to be a complimentary arrangement and/or competition between several competing weaker interactions [17]. In contrast, related series of isomorphous fluoro- $N$-(pyridyl)benzamides (Fxx) containing a range of donors/acceptors of varying strengths e.g. $\mathrm{CON}(\mathrm{H})$ have been reported by us previously $[10,18]$.
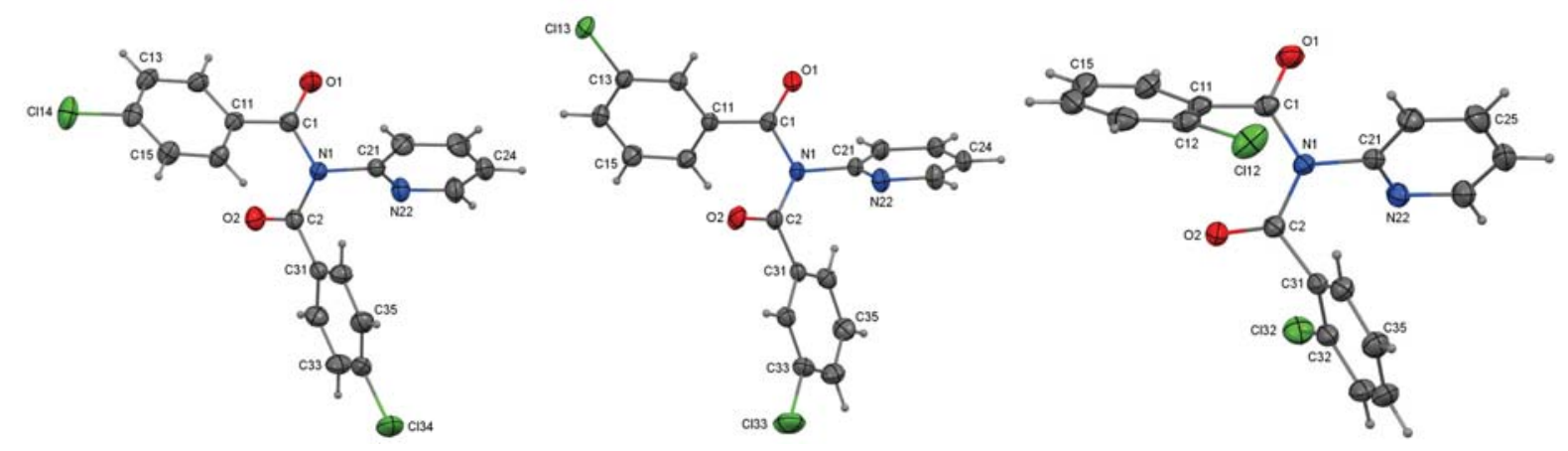

Figure 2. Views of the three Clxod structures with the atomic numbering scheme and with displacement ellipsoids drawn at the $30 \%$ probability level; $\mathrm{H}$ atoms are drawn as spheres of an arbitrary size. 
In Clpod the significant intermolecular hydrogen bonding interactions involve two $\mathrm{C}-\mathrm{H} \cdots \mathrm{O}$, a $\mathrm{C}-\mathrm{H} \cdots \mathrm{N}_{\text {pyridine }}$ and a $\mathrm{C}-\mathrm{H} \cdots \pi$ (arene) contact per molecule. The $\mathrm{C} 24-\mathrm{H} 24 \cdots \mathrm{O} 2^{\mathrm{ii}}$ and $\mathrm{C} 25-$ $\mathrm{H} 25 \cdots \pi$ (arene) $)^{\mathrm{ii}}$ interactions link molecules as 1-D chains along the $c$-axis direction that associate further about inversion centres into a zipper (comprising two chains) by reciprocal $\mathrm{C} 12-\mathrm{H} 12 \cdots \mathrm{O}^{i}$ contacts involving $\mathrm{C} 12$ about inversion centres (Table $2 \mathrm{a}$ ). These are linked by

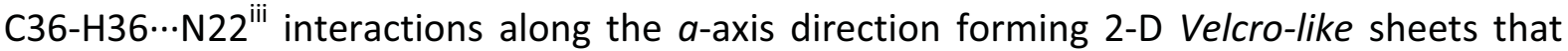
interlock to produce a 3-D structure. In addition, weak $\mathrm{Cl} 14 \cdots \mathrm{Cl} 14^{\mathrm{xii}}$ intermolecular halogen contacts with $\mathrm{Cl} \cdots \mathrm{Cl}=3.3396(9) \AA$ and $\mathrm{C} 14-\mathrm{Cl} 14 \cdots \mathrm{Cl} 14^{\mathrm{xii}}=156.06(7)^{\circ}\left[N_{\mathrm{c}}=0.95\right]$ arise about inversion centres (symmetry code: $x i i=1-x,-y, 1-z$ ) and shorter than the van der Waals contact distance (3.50 ̊). Halogen $\cdots$ Halogen contacts such as $\mathrm{Cl} \cdots \mathrm{Cl}$ are well known [19] and have been observed in related structures such as a chlorinated trezimide [8] $\left(\mathrm{ClIO}_{3}\right.$ with intermolecular $\mathrm{Cl} \cdots \mathrm{Cl}$ distances of 3.165(3) A. Recently, Kukushkin and co-workers have commented on the role of $\mathrm{Cl} \cdots \mathrm{Cl}$ interactions involving halomethanes $\left(\mathrm{CH}_{2} \mathrm{Cl}_{2}, \mathrm{CH}_{2} \mathrm{Br}_{2}\right)$ with metal centres and halide anions $\left(\mathrm{Cl}^{-}, \mathrm{Br}^{-}\right)[20,21]$.
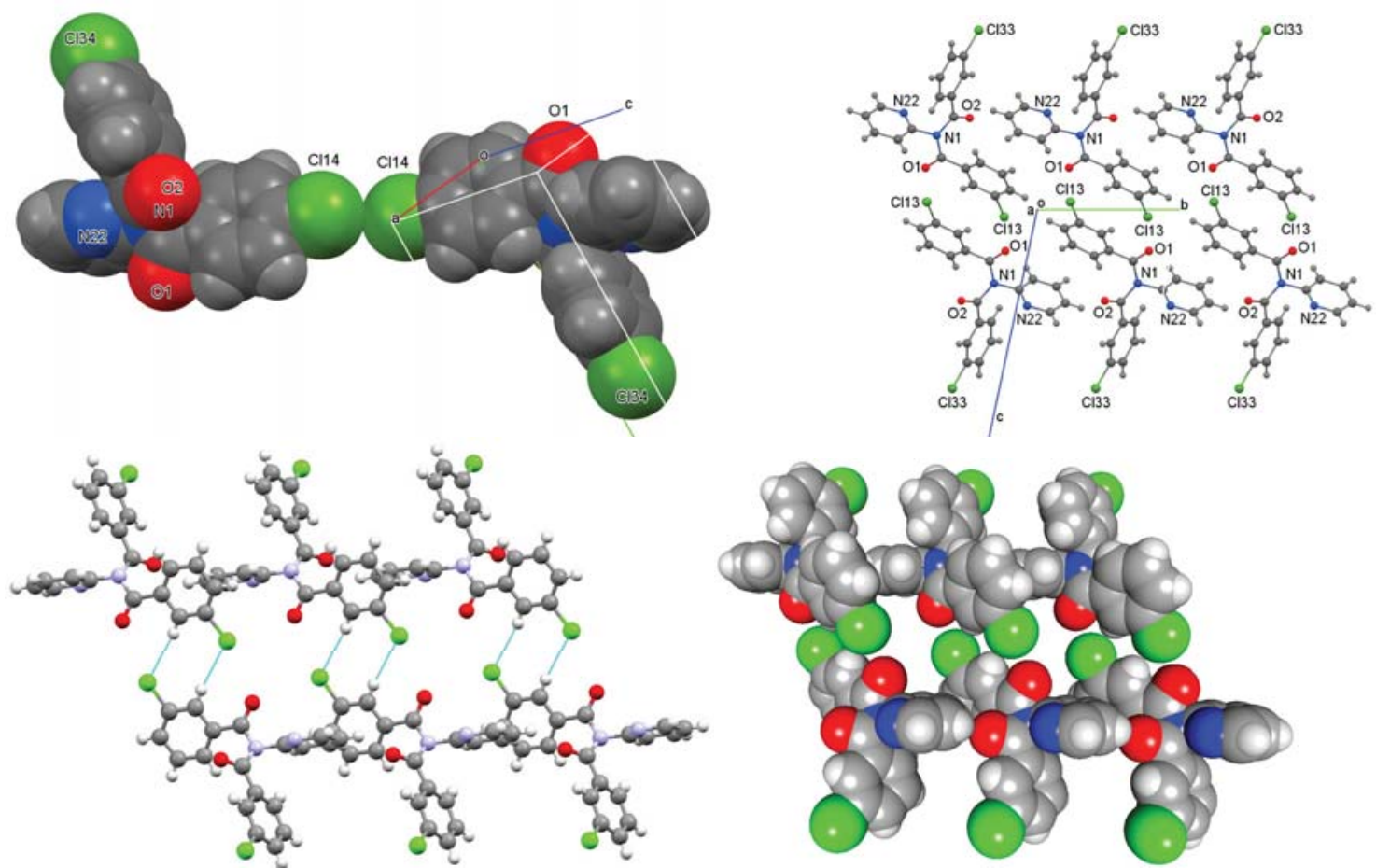

Figure 3. $\mathrm{Cl} \cdots \mathrm{Cl}$ contacts in Clpod (top, left) and $\mathrm{C}-\mathrm{H} \cdots \mathrm{O}$ contacts in Clmod (top, right) and with cyclic $\mathrm{C}-\mathrm{H} \cdots \mathrm{Cl}$ interactions in Clmod as an auto-stereogram (bottom right) [22].

Molecules of Clmod associate by weak $\mathrm{C}-\mathrm{H} \cdots \mathrm{Cl}$ hydrogen bonding contacts (as $\mathrm{C} 12$ $\mathrm{H} 12 \cdots \mathrm{Cl} 13^{\mathrm{v}}$ ) about inversion centres forming $R^{2}{ }_{2}(8)$ rings $\left[N_{\mathrm{c}}=0.96\right]$. Dimers aggregate by translation via bifurcated $(\mathrm{C}-\mathrm{H})_{2} \cdots \mathrm{O}=\mathrm{C}\left[R^{1}{ }_{2}(5)\right]$ rings as $\{(\mathrm{C} 24-\mathrm{H} 24 / \mathrm{C} 25-\mathrm{H} 25)\} \cdots(\mathrm{O} 2=\mathrm{C} 2)^{\text {iv }}$ forming a 1-D molecular tape (zipper) comprising two chains (Table 2 b) parallel with (-111). The bifurcated interaction is of interest and a regular feature in structural carbonyl chemistry [23]. An alternate description is the formation of 1-D chains by $(\mathrm{C}-\mathrm{H})_{2} \cdots \mathrm{O}=\mathrm{C}$ that further link into tapes about inversion centres by $\mathrm{C}-\mathrm{H} \cdots \mathrm{Cl}$ contacts. There are no other important intermolecular interactions. Of further note is that Clmod is isomorphous with the related 3-Fluoro- $N$-(3-fluorobenzoyl)- $N$-(2-pyridyl)benzamide (Fmod) crystal structure in space group $P \overline{\mathbf{1}}$ [5]. This is not surprising and isomorphous relationships are well explored and regularly reported $[10,18]$ with many examples present on the CSD [23]. 
The Clood crystal structure comprises four long $\mathrm{C}-\mathrm{H} \cdots \mathrm{O}$ interactions per molecule linking Clood molecules into a 2D sheet parallel with the (001) plane and incorporating $\pi \cdots \pi$ (arene) stacking and partial aromatic ring overlap about inversion centres $\left(C 14 \cdots C 14^{\mathrm{vi}}=3.331(3) \AA\right.$ : symmetry codes, Table $2 \mathrm{c}$ ). The four weak $\mathrm{C}-\mathrm{H} \cdots \mathrm{O}$ interactions have $\mathrm{C} \cdots \mathrm{O}$ distances in a range from $3.38 \AA$ to $3.51 \AA$, with $\mathrm{C}-\mathrm{H} \cdots \mathrm{O}$ angles of $150-170^{\circ}$ (Table 2c). The molecular aggregation can be interpreted as $\mathrm{C} 13-\mathrm{H} 13 \cdots \mathrm{O} 1^{\mathrm{iii}}$ hydrogen bonds forming $1 \mathrm{D}$ chains along the $a$-axis direction, further linked by $\mathrm{C} 26-\mathrm{H} 26 \cdots \mathrm{O} 1^{\text {viii }}$ interactions about inversion centres. The chains aggregate into $2 \mathrm{D}$ sheets by the $\mathrm{C} 14-\mathrm{H} 14 \cdots \mathrm{O} 2^{\mathrm{vi}}$ and $\mathrm{C} 16-\mathrm{H} 16 \cdots \mathrm{O} 2^{\mathrm{vii}}$ interactions. Of note is the formation of a $\mathrm{C}-\mathrm{H} \cdots \mathrm{O}$ hydrogen bonded ring involving three molecules with graph set $R_{2}^{2}(10)$, incorporating the $\mathrm{C} 12-\mathrm{H} 12, \mathrm{C} 13-\mathrm{H} 13$ and $\mathrm{C} 16-\mathrm{H} 16$ donor groups (Figure 4). This compact arrangement is further strengthened by reciprocal hydrogen bonding between adjacent Clood molecules.
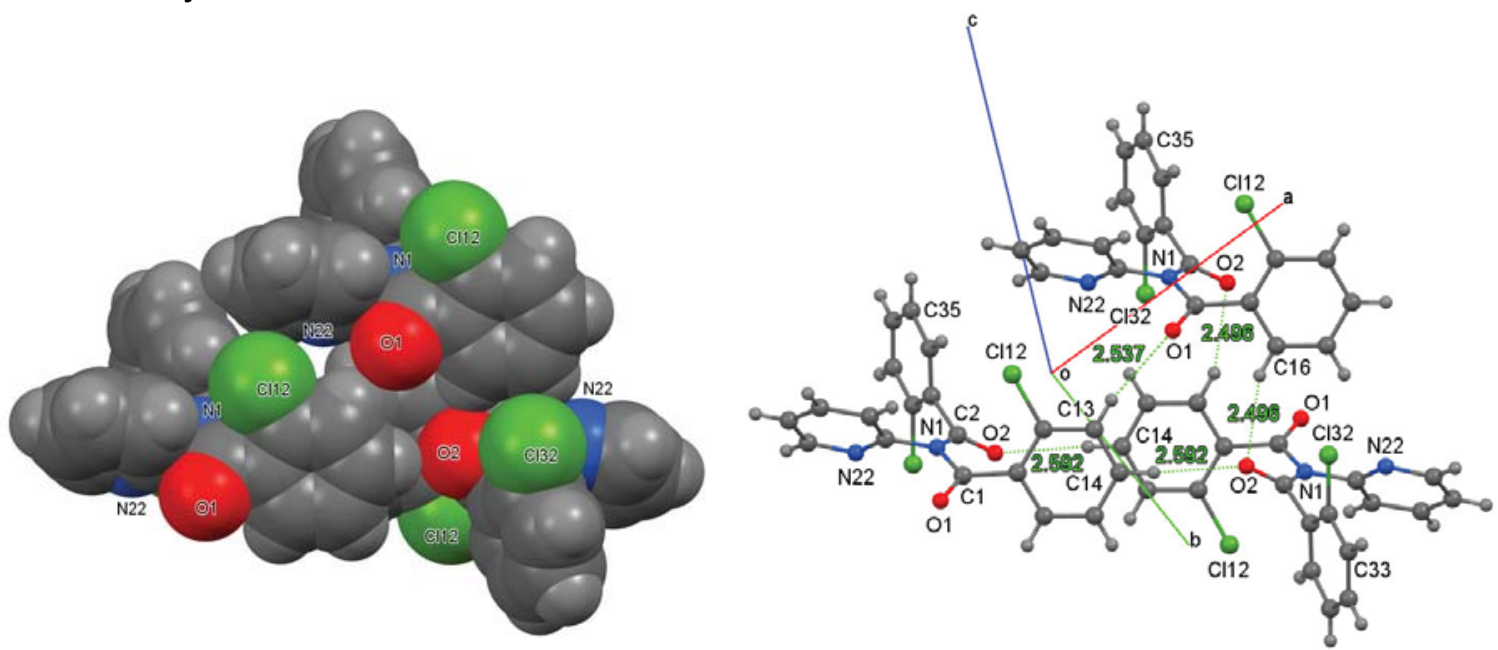

Figure 4. A hydrogen bonded trimer in Clood showing the $\mathrm{C}-\mathrm{H} \cdots \mathrm{O}$ interactions and depicted as CPK model and with ellipsoids (30\%) for the non-hydrogen atoms.

In summary, three Clxod isomers (with donors and acceptors differing only in the spatial orientation of $\mathrm{Cl} / \mathrm{H}$ groups in the benzene rings as directed para-, meta- or ortho-) aggregate using a variety of weaker intermolecular interactions from a combination of weak donors and strong/weaker acceptor atoms/groups. This gives rise to a varied combination of C$\mathrm{H} \cdots \mathrm{Cl} / \mathrm{O} / \mathrm{N}$ hydrogen bonds, $\mathrm{Cl} \cdots \mathrm{Cl}$ contacts and $\pi \cdots \pi$ stacking interactions in the three Clxod crystal structures. Analysis using enrichment studies provides further information on the important interactions in Clxod crystal structure formation.

\subsection{Enrichment studies - Clxod structures}

Hirshfeld surface analysis of the Clxod isomers was undertaken with the MoProViewer software [24] to further characterize the intermolecular contacts. The surface is representative of the region in space where molecules/atoms come into contact. Therefore, quantitative insights into the chemical nature of intermolecular interactions in the crystalline state can be obtained by analysis. The prominent elements on the Hirshfeld surface are hydrogen followed by carbon whose proportions together account for and sum to $70-75 \%$ in the three Clxod isomers (Table 3 ). In all cases, the most abundant contact type is $\mathrm{C} \cdots \mathrm{H}$ in the range $26-30 \%$ due to the abundance of the two elements on the respective Clxod molecular surfaces. 
Table 3. Statistics on contacts in the Clxod isomers.

\begin{tabular}{|c|ccccc|}
\hline Atom & $\mathbf{H}$ & $\mathbf{C}$ & $\mathbf{N}$ & $\mathbf{O}$ & $\mathbf{C l}$ \\
\hline \% surf & 38.5 & 31.6 & 2.2 & 8.2 & 19.5 \\
\hline $\mathrm{H}$ & 0.64 & & & & \\
$\mathrm{C}$ & 1.10 & 1.04 & & & Clpod \\
$\mathrm{N}$ & 2.49 & 0.09 & 0.00 & & \\
$\mathrm{O}$ & 1.62 & 0.45 & 0.00 & 0.00 & \\
$\mathrm{Cl}$ & 1.14 & 1.06 & 0.00 & 1.15 & 0.69 \\
\hline \% surf & 37.7 & 32.2 & 2.5 & 7.6 & 19.9 \\
\hline $\mathrm{H}$ & 0.50 & & & & \\
$\mathrm{C}$ & 1.21 & 0.83 & & & Clmod \\
$\mathrm{N}$ & 2.25 & 0.34 & 0.00 & & \\
$\mathrm{O}$ & 1.57 & 0.73 & 0.00 & 0.00 & \\
$\mathrm{Cl}$ & 1.31 & 1.04 & 0.02 & 0.79 & 0.51 \\
\hline \% surf & 42.4 & 32.0 & 1.8 & 8.1 & 15.7 \\
\hline $\mathrm{H}$ & 0.73 & & & & \\
$\mathrm{C}$ & 1.07 & 0.97 & & & Clood \\
$\mathrm{N}$ & 2.15 & 0.01 & 0.00 & & \\
$\mathrm{O}$ & 2.04 & 0.17 & 0.00 & 0.22 & \\
$\mathrm{Cl}$ & 0.93 & 1.38 & 0.50 & 0.35 & 0.81 \\
\hline
\end{tabular}

* Footnote: The proportion of chemical elements on the Hirshfeld surface is shown with enrichment Exy values of intermolecular contacts between chemical species in the three Clxod crystal packings. The enriched weak hydrogen bonds $\mathrm{O} \cdots \mathrm{H}-\mathrm{C}$ and $\mathrm{N} \cdots \mathrm{H}-\mathrm{C}$ are highlighted. Reciprocal contacts $X \cdots Y$ and $Y \cdots X$ are merged.

The contact enrichment ratio is an indicator of the likelihood of chemical species to form intermolecular interactions with themselves and other species [25]. In the three crystal structures, the $\mathrm{N} \cdots \mathrm{H}-\mathrm{C}$ interactions followed by the $\mathrm{O} \cdots \mathrm{H}-\mathrm{C}$ interactions are the most enriched $\left(E_{\mathrm{HN}}>2.15\right)$, indicating that these weak hydrogen bonds are still the strongest interactions and the driving force in the crystal packing formation. Globally the hydrophobic contacts $\mathrm{C} \cdots \mathrm{H}$ are slightly enriched, $\mathrm{C} \cdots \mathrm{C}$ contacts are not far from $E_{\mathrm{CC}}=1$. Conversely, the $\mathrm{H} \cdots \mathrm{H}$ contacts are significantly impoverished as $\mathrm{H}$ atoms are required as hydrogen bonding donors to the $\mathrm{N}$ and $\mathrm{O}$ acceptor atoms. The $\mathrm{C}-\mathrm{H}$ hydrogen was found to be generally a favorable partner of organic halogen X-C atoms [25] and this is the case for the Clmod (1.31) and Clpod (1.14) crystal structures, but not for Clood (0.93) where $\mathrm{H} \cdots \mathrm{Cl}$ contacts are slightly under-represented.

Interactions among the $\mathrm{O}$ and $\mathrm{N}$ electronegative atoms are systematically avoided in the three crystal packings (with $E$ equal or close to zero). The contacts of organic chlorine which is both hydrophobic and slightly electronegative interacting with $\mathrm{Cl}, \mathrm{O}$ and $\mathrm{N}$ atoms are also generally under-represented (Table 3). A notable exception is the Clpod structure (Figure 5) for which $\mathrm{Cl} \cdots \mathrm{O}$ contacts are incidentally slightly enriched, due to two mere contacts which are longer than the van der Waals distance $(3.27 \AA)$; these are not halogen bonds (the shortest $\mathrm{Cl} 14 \cdots 01^{\mathrm{xiii}}=3.4254(15) \AA ̊$ : symmetry code: $\mathrm{xiii}=-\mathrm{x},-\mathrm{y},-\mathrm{z}$; footnote, Table 2). 

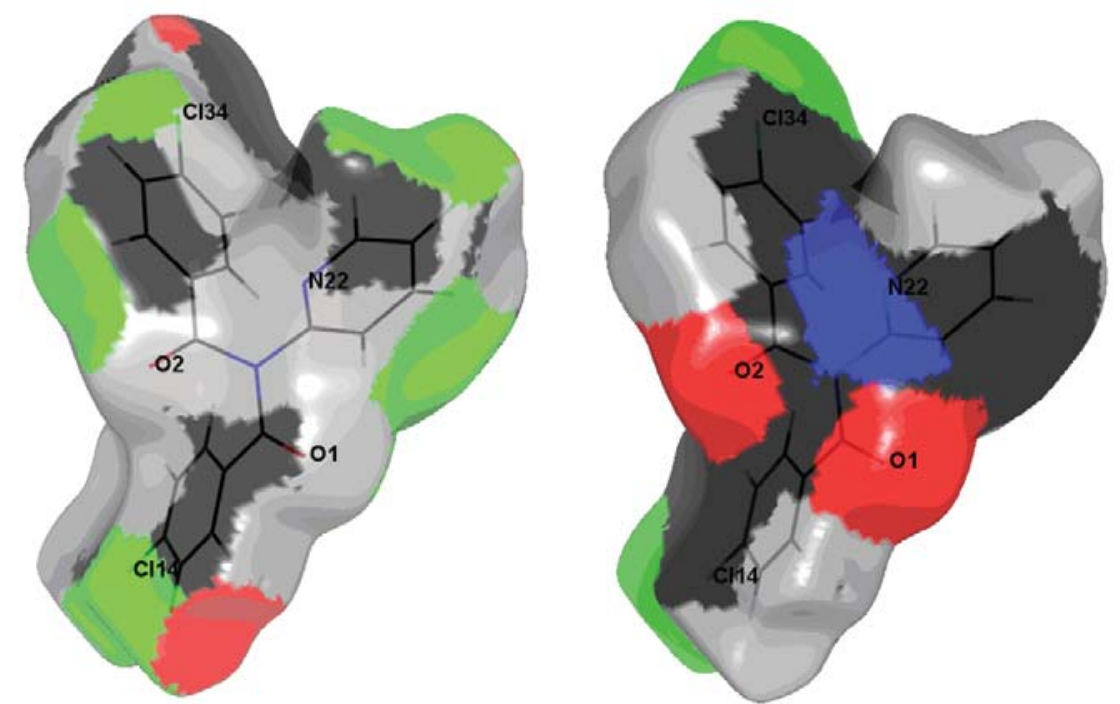

Figure 5. Hirshfeld surface of Clpod and coloured according to the exterior (left) and interior (right) atom type. Dark grey: carbon $(C)$, light grey: hydrogen $(H)$, red: oxygen $(O)$, blue: nitrogen $(\mathrm{N})$, green: chlorine $(\mathrm{Cl})$.

Globally, the correlation coefficient between actual contact surfaces in the three compounds are $94.2 \%$ for ortho-meta, $96.4 \%$ for ortho-para and $98.9 \%$ for the meta-para pairs of Clxod isomers. These high correlations are due to the identical chemical content of the molecules differing only in the spatial arrangement of $\mathrm{Cl} / \mathrm{H}$ peripheral atoms on both mono-chlorinated benzene rings. The correlations of the enrichment values are devoid of this contribution and are expected to have smaller values. The correlations between $E$ values show similar trends with $87.9 \%$ for ortho-meta, $89.3 \%$ for ortho-para and $96.9 \%$ for meta-para pairs. These high coefficients show that the three Clxod isomers have contacts of the same nature (given that they are isomers) while the Clmod and Clpod interactions are the most similar. This is also clear from the structural study where the orientation of the aromatic rings and molecular geometries of Clpod and Clmod are broadly similar and differ notably from Clood.

\subsection{Database survey}

Analysis of the Cambridge Structural Database $[23,26]$ shows that there are $c a .50$ structures incorporating the basic acyclic imide structure and with $\sim 22$ of these incorporating an imide linker moiety acting as a hinge as component parts of a macrocycle [6-8]. We conclude that the number of acyclic imides is small compared to their benzamide analogues $[4,5]$. Some imides include the Fmod and Food (2-Fluoro- $N$-(2-fluorobenzoyl)- $N$-(2-pyridyl)benzamide) fluorinated relatives $[4,5]$ that are similar in molecular structure to the three Clxod structures reported herein (Figure 2). The Fmod and Food isomers [4,5] are analogues of Clmod and Clood and with the Fmod and Clmod structures being isomorphous.

\subsection{Molecular features - Mxod structures}

The conformations adopted by the Mpod and Mmod molecules are as expected (Figure 6) and similar to Clxod with transoid (anti) orientations of the pendant tolyl groups and similar to related structures [4,5]. However, the Mood conformation differs with an o-tolyl group rotated into a cisoid (syn) conformation such that Mood adopts a more symmetrical geometry. Examination of the torsion angles at both $\mathrm{C} 1$ and $\mathrm{C} 2$ shows this clearly (Figures 6- 
7). This difference highlights the flexibility of the molecular backbone within the (Mxod) series ( $\mathrm{x}=$ para-/meta-/ortho-) (Figures 6-7; ESI Supplementary Tables).
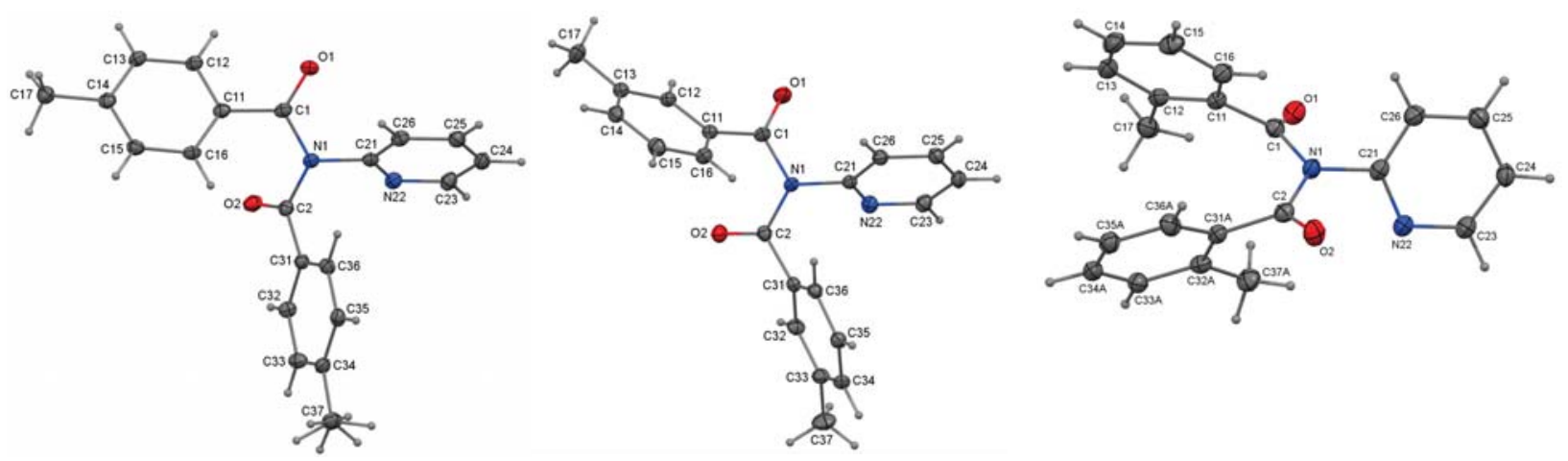

Figure 6. Views of the three Mxod structures with the atomic numbering scheme and displacement ellipsoids drawn at the $30 \%$ probability level; $\mathrm{H}$ atoms are drawn as spheres of an arbitrary size. The major cisoid-conformer of Mood is depicted for clarity (right).

The ${ }_{\mathrm{Ar}} \mathrm{C}=\mathrm{O}-\mathrm{C} \cdots \mathrm{C}_{=0}-\mathrm{C}_{\mathrm{Ar}}[\mathrm{C} 11-\mathrm{C} 1 \cdots \mathrm{C} 2-\mathrm{C} 31]$ torsion angles are $-104.05(17)^{\circ}$ and $-114.88(18)^{\circ}$ in Mpod and Mmod, respectively, and distinctly different to $54.4(2)^{\circ}$ in the major orientation of Mood (VI). In two related Fxod structures the corresponding ${ }_{A r} C_{=0} C \cdots C_{=0}-C_{A r}$ torsion angles are $119.7(3)^{\circ}$ (Fmod, meta-F) and -121.3(3)/113.9(3) ${ }^{\circ}$ (Food, ortho-F) [4,5]. In Mmod, the toluoyl carbonyl $O$ atoms and meta-methyl groups are syn-related at $33.7(2)^{\circ}, 43.4(2)^{\circ}$ (for $\mathrm{O}=\mathrm{C} \cdots \mathrm{C}-\mathrm{CH}_{3}$ ). However, in Mood one toluoyl group has syn-related meta-methyl and carbonyl atoms of $46.9(2)^{\circ}$, whereas the disordered $o$-toluoyl group [major site, $0.905(4)$ occupancy] has anti-related 0 -tolyl/carbonyl groups at $97.3(3)^{\circ}$, whereas the minor site [0.095(4) occupancy] is syn-related at $49(2)^{\circ}$. There is no evidence of a disordered carbonyl $\mathrm{O}$ atom in Mood having both oriented as anti. The Mxod carbonyl torsion angles defined by the imide hinge (as $\mathrm{O} 1=\mathrm{C} 1 \cdots \mathrm{C} 2=02$ ) are $111.8(2)^{\circ}, 104.54(18)^{\circ}$ and $84.0(5)^{\circ}$. The two former structures have conformations that are similar to Clxod and with the latter Mood structure adopting a cisoid (syn) conformation (Figure 6).

Most of the bond lengths and angles are as expected in all three Mxod structures. However, subtle differences are observed in the ' $\mathrm{O}=\mathrm{C}-\mathrm{N}-\mathrm{C}=\mathrm{O}$ ' skeleton and especially about the $\mathrm{N} 1$ atom. In Mpod the imide N1-C1 [1.408(2) A]] is shorter than N1-C2 [1.4393(19) $\AA$ ] by 0.031 $\AA$ : this situation is reversed in Mmod with N1-C1 [1.4271(18) $\AA$ ] slightly longer by $0.02 \AA$ than N1-C2 [1.4076(18) $\AA$ ]. In Mood, this bond length alteration is less dramatic with N1-C1 $=1.421(2) \AA$ and N1-C2 $=1.407(3) \AA$. This is presumably influenced by the ortho-tolyl group disorder. The three corresponding N1-C21 bond lengths are similar: 1.435(2), 1.4410(18) and $1.443(3) \AA$, and together with three sets of similar $C=0$ bond lengths as would be expected. The $\mathrm{N}-\mathrm{C}$ bond length differences are surprising considering that they are equivalent bonds and for the Mpod, Mmod structures are in similar overall conformations (ESI, Supplementary Table 2). The corresponding data for Clxod are not as dramatic with average differences of $0.012 \AA$. In addition, for Mxod, the N1-C1-C11 angles vary as $118.98(13)^{\circ}, 116.47(12)^{\circ}, 116.0(2)^{\circ}$ : the N1-C2-C31 angles as $115.36(13)^{\circ}, 116.10(11)^{\circ}$, $118.2(2)^{\circ}(\mathrm{A})$, while the central C1-N1-C2 angles differ as $122.92(13)^{\circ}, 119.73(11)^{\circ}, 122.8(2)^{\circ}$. What is the explanation for the bond length/angle alteration in Mxod? 
What is the cause of this effect?

The subtle, though distinct differences in geometric data in the imide core highlights bond length/angle alteration for similar conformations. Hydrogen bonding effects can be ruled out as the $\mathrm{C}=\mathrm{O}$ groups only participate in weak $\mathrm{C}-\mathrm{H} \cdots \mathrm{O}=\mathrm{C}$ contacts, with the $\mathrm{C}=\mathrm{O}$ bond lengths being barely perturbed. The bond length/angle alterations are influenced by orbital overlap and disposition of the pyridyl groups with respect to the central imide group. Imide group analysis for Mpod shows that atoms in the (C11/C1/O1/N1/C21) plane are effectively co-planar (N1 deviates by $0.037(1) \AA$ ), contrasting with the more distorted (C31/C2/O2/N1/C21) plane (where N1 deviates by $0.464(11) \AA$ ). There is greater multiple bond character in N1-C1 (essentially planar group geometry) than in N1-C2 which is part of more distorted imide group. Analysis of Mmod and Mood (ESI) shows the relevant 5-atom planes to exhibit intermediate levels of distortion and non-planar geometry.
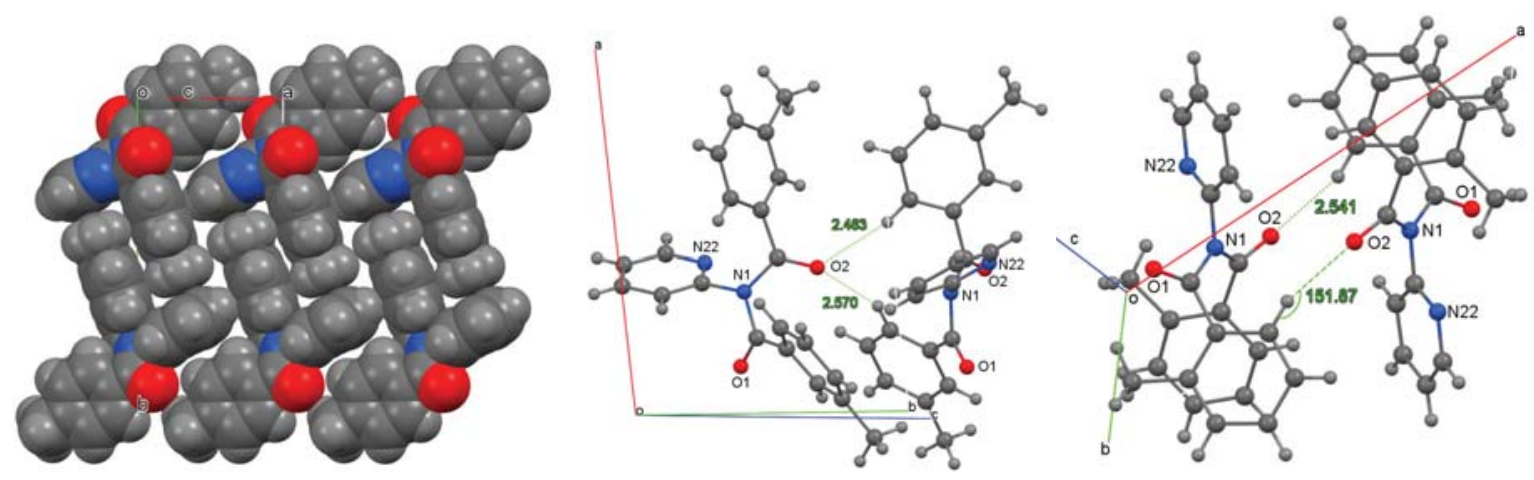

Figure 7. Aggregation in Mpod by $\mathrm{C}-\mathrm{H} \cdots \mathrm{O} / \pi$ contacts with atoms as van der Waals spheres (above, left) and views of the two $\mathrm{C}-\mathrm{H} \cdots \mathrm{O}$ contacts in Mmod (above, middle) and the cyclic $\mathrm{C}-\mathrm{H} \cdots \mathrm{O}$ interactions in the major conformer of Mood (above, right).

\subsection{Supramolecular features - Mxod structures}

There are no classical hydrogen bonds in either of the three Mxod crystal structures as noted already for Clxod. The strongest interactions are typically $\mathrm{C}-\mathrm{H} \cdots \mathrm{O}=\mathrm{C}, \mathrm{C}-\mathrm{H} \cdots \pi$ (arene) and $\pi \cdots \pi$ stacking (Figure 7 ) in the Mxod structures that lack strong hydrogen bond donors. In Mpod, $\mathrm{C}-\mathrm{H} \cdots \mathrm{O}=\mathrm{C}$ interactions form along the $a$-axis direction with $\mathrm{C} 17 \cdots \mathrm{O} 1^{\mathrm{iii}}=3.317(2) \AA$, and combined with the $\mathrm{C} 24-\mathrm{H} 24 \cdots \pi(\mathrm{C} 31 \ldots \mathrm{C} 36)^{\mathrm{xiv}}$ interactions form one-dimensional chains along [100] with $\mathrm{H} 24 \cdots \mathrm{Cg} 3^{\text {xiv }} 2.63 \AA$, $\mathrm{C} 24 \cdots \mathrm{Cg} 3^{\text {xiv }} 3.5082(18) \AA$ : weaker $\mathrm{C}-\mathrm{H} \cdots \mathrm{O}$ and $\pi \cdots \pi$ stacking contacts complete the crystal structure.

In Mmod a cyclic hydrogen bonded ring system involving the $\mathrm{C}=\mathrm{O}$ atom $\mathrm{O} 2$ with $\mathrm{C} 16$ and C36 is noted with graph set $\mathrm{R}_{2}{ }_{2}(10)$. Weak $\mathrm{C} 26-\mathrm{H} 26 \cdots \pi(\mathrm{C} 11 \ldots \mathrm{C} 16)^{\mathrm{ix}}$ interactions also form about inversion centres, with $\pi \cdots \pi$ stacking interactions arising between the inversion symmetry related C25 atoms with $C 25 \ldots C 25^{\text {viii }}=3.351(2) \AA$ (Table 2; Figure 7).

In Mood, several $\mathrm{C}-\mathrm{H} \cdots \mathrm{O}$ contacts have little influence on the structure or packing apart from $\mathrm{C}_{16} \cdots \mathrm{O}^{\mathrm{vii}}$ about inversion centres. There are many minor, partial occupancy interactions due to the $o$-tolyl group disorder (Table 2). These results highlight once again the formation of weaker interactions where strong hydrogen bonding donors are absent and the competition amongst weaker interactions to influence aggregation. 


\subsection{Enrichment studies on the Mxod structures}

Table 4. Statistics on enrichment contacts in the Mxod isomers.

\begin{tabular}{|c|cccc|}
\hline Atom & H & C & N & O \\
\hline \% surf & 55.0 & 34.9 & 2.6 & 7.5 \\
\hline H & 0.73 & & & \\
C & 1.27 & 0.81 & & Mmod \\
N & 1.49 & 0.18 & & \\
O & 1.74 & 0.00 & 0.00 & 0.00 \\
\hline \% surf & 56.3 & 33.8 & 2.0 & 8.0 \\
\hline H & 0.66 & & & \\
C & 1.36 & 0.65 & & Mpod \\
N & 1.78 & 0.03 & & \\
O & 1.60 & 0.32 & 0.00 & 0.00 \\
\hline \% surf & 59.0 & 30.6 & 2.4 & 8.1 \\
\hline H & 0.84 & & & \\
C & 1.14 & 0.94 & & Mood \\
N & 1.57 & 0.20 & & \\
O & 1.48 & 0.39 & 0.00 & 0.00 \\
\hline
\end{tabular}

Footnote: $\mathrm{N} \cdots \mathrm{N}$ is omitted due to the small $\mathrm{N}$ content on the surface.

The Mxod isomers have at least 55\% hydrogen on their surface, followed by carbon at 30 $35 \%$. Consequently, the most abundant contact type is $\mathrm{C} \cdots \mathrm{H}$ in the range $40-52 \%$. Compounds Mmod and Mpod have very similar actual contacts types (correlation 99.2\%) while the correlations for the (Mpod, Mood) and (Mmod, Mood) pairs are $95.5 \%$ and 97.9\%, respectively. The contact enrichment ratios between the Mxod isomers show correlations in the $96.6-97.4 \%$ range.

The $\mathrm{C}-\mathrm{H} \cdots \mathrm{O}$ and $\mathrm{C}-\mathrm{H} \cdots \mathrm{N}$ weak hydrogen bonds are the strongest interactions in the three Mxod crystal structures and their enrichment values are highest in the 1.48-1.78 range (Table 4). The $\mathrm{N} \cdots \mathrm{O}, \mathrm{O} \cdots \mathrm{O}$ and $\mathrm{N} \cdots \mathrm{N}$ contacts between electronegative species are mostly absent, except for the case of Mpod which has $0.2 \%$ of $\mathrm{N} \cdots \mathrm{N}$ contacts. In all three Mxod isomers, the occurrence of both $\mathrm{H} \cdots \mathrm{H}$ and $\mathrm{C} \cdots \mathrm{C}$ non-polar contacts are moderately impoverished. On the other hand, the $\mathrm{C} \cdots \mathrm{H}$ interactions are slightly enriched ( $E=1.1-1.21)$, as for the Clxod crystal structures, as all $\mathrm{H}$ atoms are mildly positively charged and most carbon atoms are weakly electronegative for Mxod and Clxod.

\subsection{Structural Summary and comparisons}

Acyclic imides are relatively rare compared to the vast number of benzamides available $[23,26]$. The six Clxod and Mxod structures show a general trend for acyclic imides adopting an open or transoid structure with only Mood noted to have the cisoid-type structure. The $\mathrm{N}$-(3-bromo-1,4-dioxo-1,4-dihydro-2-naphthyl)-2-chloro- $N$-(2-chlorobenzoyl)-benzamide and $\mathrm{N}$-(3-bromo-1,4-dioxo-1,4-dihydro-2-naphthyl)-4-fluoro-N-(4-fluorobenzoyl)-benzamides, QOLROZ and GOLHIZ [27,28], respectively, differ from Mxod in having the chloro-1,4- 
naphthoquinone skeletons. Other imide structures include the ferrocene ZEQDOO and MARVEG derivatives, synthesised from a bis-acylchloride $\mathrm{Fc}(\mathrm{COCl})_{2}\left(\mathrm{Fc}=\mathrm{Fe}\left(\mathrm{C}_{5} \mathrm{H}_{4}\right)_{2}\right)[29,30]$ which exhibit the relative geometry of substituted $R C O N\left(R^{\prime}\right) C O R$ systems. The bis(ferrocenoyl)pyridine derivative VIHVAK is synthesized by reacting $\mathrm{FcCOCl}$ with 0 aminopyridine $[23,26,31]$, and has a geometry about the central imide $\mathrm{O}=\mathrm{C}-\mathrm{N}(\mathrm{R})-\mathrm{C}=\mathrm{O}$ core that is similar to (Mood). This may be the most favourable conformation from a steric viewpoint, but it is actually enforced in the ZEQDOO, MARVEG structures $[29,30]$. Recently, Valkonen and co-workers reported the substituted diimide tetrakis $(2,3,4,5,6$ pentafluorobenzoyl)pyridine-2,6-diamine or OCAZAV [26,32] with imide conformations that are similar to Mpod and Mmod. Overall, we can conclude that there is a tendency for acyclic imides such as Clxod or the Mpod, Mmod pair to have a more open anti-conformation but that it is possible to isolate the syn-conformation as in Mood and without it being sterically forced, as seen in MARVEG and ZEQDOO [29,30].

The imide $\mathrm{O}=\mathrm{C} \cdots \mathrm{C}=\mathrm{O}$ torsion angle data are comparable to the related macrocyclic trezimides and tennimides [6-8]. For these systems the corresponding imide hinge angles (labelled originally as the 'CO $\cdots$ CO' imide twist angles) are typically in the range $85^{\circ}$ to $115^{\circ}$ and usually between $95^{\circ}$ and $105^{\circ}$. For (I)-(III) these 'CO $\cdots$ CO' angles are $98.2(2)^{\circ}, 105.8(2)^{\circ}$, $127.6(2)^{\circ}$ and in (IV)-(VI) are $111.8(2)^{\circ}, 104.54(18)^{\circ}$ and $84.0(5)^{\circ}$. This highlights that the Clpod, Clmod, Mpod and Mmod molecular structures are generally within the range as noted in the macrocycles [6-8] but with Clood and Mood as outliers for two different reasons. Clood is influenced by the steric effect of the ortho- $\mathrm{Cl}$ and the corresponding imide hinge 'CO $\cdots \mathrm{CO}^{\prime}$ increases by $\sim 10-15^{\circ}$ over what would normally be expected. Mood adopts the cisoid arrangement and is comparable with $86.7^{\circ}$ (ZEQDOO) [29] and $100.2^{\circ}$ (VIHVAK) [31]. Overlay of pairs of the Mxod structures (ESI: overlay diagrams) shows that the two principal imide geometries feature as a subset of the imide hinges known in both trezimides and tennimide macrocycles although the transoid conformation dominates and is the principal driving force behind cyclisation on geometric grounds. A greater understanding of the role of the imide hinge (as the 'CO $\cdots \mathrm{CO}^{\prime}$ imide torsion angle) is warranted in understanding macrocycle vs oligomer/polymer formation and the present study builds on our knowledge of the acyclic imide functional group.

\section{Conclusion}

The paper reports on the crystal structures of six acyclic imides and augments our knowledge of the factors that influence conformation and aggregation in acyclic imides $[4,5]$. It also facilitates a more comprehensive understanding of geometries, the variety and range in acyclic imides that form key components in the trezimide and tennimide macrocycles as well as in oligomeric and polymeric imides [6-8]. The use of both structural analyses and contact enrichment studies to analyse the six Clxod, Mxod imide structures is highlighted and serves to demonstrate the key interactions that are available and involved in imide aggregation.

\section{Future work}

The synthesis of new acyclic imides will add to the body of structural knowledge on acyclic imide conformations and therefore aid in the design of imides that can be incorporated into larger ring size trezimide and tennimide macrocycles [6-8]. The synthesis of longer acyclic imide oligomers and polymers is also planned. 


\section{Supplementary Information}

Crystallographic data for the six Clxod and Mxod isomeric crystal structures have been deposited with the Cambridge Crystallographic Data Centre, CCDC no. 1564570 to 1564575. The CIF data may be downloaded from the CCDC website https://www.ccdc.cam.ac.uk/deposit/upload or obtained free of charge from The Director, CCDC, 12 Union road, Cambridge, CB2 1EZ, U.K. (fax: +44-1223-336033; e-mail: deposit@ccdc.cam.ac.uk). The data are also available as CIF files from the corresponding author Dr. John F. Gallagher.

\section{Acknowledgements}

JFG and MF thank Dublin City University for grants in aid of undergraduate research. PM thanks the $T^{3}$ (PRTLI-4) program for a postgraduate studentship. This research was partfunded by the Programme for Research in Third Level Institutions (PRTLI) Cycle 4 (Ireland) and co-funded through the European Regional Development Fund (ERDF), part of the European Union Structural Funds Programme (ESF) 2007-2013. JFG and CJ thank the Region Lorraine for a FEDER Chercheur d'Avenir grant (2015-2018). Conflict of Interest: The authors declare that they have no conflict of interest. 


\section{References:}

1. Marckwald W (1894) Untersuchungen in der Pyridinreihe. Ber Dtsch Chem Ges 27:1317-1339. doi:10.1002/cber.18940270226

2. Tschitschibabin AE, Bylinkin JG (1922) Concerning the benzoylation products of alpha-aminopyridin. Berichte Der Deutschen Chemischen Gesellschaft 55:998-1002. doi:10.1002/cber.19220550423

3. Evans LS, Gale PA (2004) Imide linked '4+4' macrocycles formed by condensation of isophthaloyl dichloride and tetra- or penta-fluoroaniline. Chemical Communications (11):1286-1287. doi:10.1039/b401614a

4. Gallagher JF, Donnelly K, Lough AJ (2009) 2-Fluoro-N-(2-fluorobenzoyl)-N-(2-pyridyl)benzamide. Acta Crystallographica Section E-Structure Reports Online 65:0486-U1501. doi:10.1107/s1600536809002189

5. Gallagher JF, Donnelly K, Lough AJ (2009) 3-Fluoro-N-(3-fluorobenzoyl)-N-(2-pyridyl)benzamide. Acta Crystallographica Section E-Structure Reports Online 65:0102-U2157. doi:10.1107/s1600536808041093

6. Mocilac P, Gallagher JF (2013) Trezimides and Tennimides: New Imide-Based Macrocycles. Journal of Organic Chemistry 78 (6):2355-2361. doi:10.1021/jo302448h

7. Mocilac P, Gallagher JF (2014) Halogen bonding directed supramolecular assembly in bromosubstituted trezimides and tennimides. Crystengcomm 16 (10):1893-1903. doi:10.1039/c3ce42168f

8. Mocilac P, Gallagher JF (2016) Halogenated tennimides and trezimides: impact of halogen bonding and solvent role on porous network formation and inclusion. Crystengcomm 18 (13):2375-2384. doi:10.1039/c5ce02052b

9. Sharma S, Thorat SH, Gonnade RG, Jasinski JP, Butcher R, Haridas V (2017) Engineering Molecular Topology: A Pseudopeptidic Macrocyclic Figure-Eight Motif. European Journal of Organic Chemistry (7):1120-1124. doi:10.1002/ejoc.201601365

10. Donnelly K, Gallagher JF, Lough AJ (2008) Assembling an isomer grid: the isomorphous 4-, 3- and 2-fluoro-N'-(4-pyridyl)benzamides. Acta Crystallographica Section C-Crystal Structure Communications 64:0335-0340. doi:10.1107/s0108270108012067

11. Sheldrick GM (2015) Crystal structure refinement with SHELXL. Acta Crystallographica Section CStructural Chemistry 71:3-8. doi:10.1107/s2053229614024218

12. Clark RC, Reid IS (1998) ABSFAC: a program for the calculation of the absorption during scattering in multifaceted crystals and similar samples. Computer Physics Communications 111 (13):243-257. doi:10.1016/s0010-4655(98)00015-0

13. Diffraction Oxford (2010) CrysAlis CCD and CrysAlis RED. 1.172.33.55 edn. Oxford Diffraction,, Yarnton, Oxfordshire, U.K 
14. McArdle P (1995) SORTX - a program for on-screen stick-model editing and autosorting of SHELX $\begin{array}{llllll}\text { files for use on a PC. Journal of Applied Crystallography } 28 & \text { (1):65. }\end{array}$ doi:doi:10.1107/S0021889894010642

15. Spek AL (2009) Structure validation in chemical crystallography. Acta Crystallographica Section DBiological Crystallography 65:148-155. doi:10.1107/s090744490804362x

16. Macrae CF, Edgington PR, McCabe P, Pidcock E, Shields GP, Taylor R, Towler M, van De Streek J (2006) Mercury: visualization and analysis of crystal structures. Journal of Applied Crystallography 39:453-457. doi:10.1107/s002188980600731x

17. Desiraju GR, Steiner T (1999) The Weak Hydrogen Band in Structural Chemistry and Biology. Oxford University Press, Oxford

18. Mocilac P, Donnelly K, Gallagher JF (2012) Structural systematics and conformational analyses of a $3 \times 3$ isomer grid of fluoro- $\mathrm{N}$-(pyridyl)benzamides: physicochemical correlations, polymorphism and isomorphous relationships. Acta Crystallographica Section B-Structural Science 68:189-203. doi:10.1107/s0108768112006799

19. Bui TTT, Dahaoui S, Lecomte C, Desiraju GR, Espinosa E (2009) The Nature of Halogen $\cdots$ Halogen Interactions: A Model Derived from Experimental Charge-Density Analysis. Angewandte ChemieInternational Edition 48 (21):3838-3841. doi:10.1002/anie.200805739

20. Ivanov DM, Novikov AS, Ananyev IV, Kirina YV, Kukushkin VY (2016) Halogen bonding between metal centers and halocarbons. Chemical Communications 52 (32):5565-5568. doi:10.1039/C6CC01107A

21. Ivanov DM, Kinzhalov MA, Novikov AS, Ananyev IV, Romanova AA, Boyarskiy VP, Haukka M, Kukushkin VY (2017) H2C(X)- X - XX- $(X=\mathrm{Cl}, \mathrm{Br})$ Halogen Bonding of Dihalomethanes. Crystal Growth \& Design 17 (3):1353-1362. doi:10.1021/acs.cgd.6b01754

22. Katrusiak A (2001) Crystallographic autostereograms. Journal of Molecular Graphics \& Modelling 19 (3-4):363-367. doi:10.1016/s1093-3263(00)00085-1

23. Groom CR, Bruno IJ, Lightfoot MP, Ward, SC (2016) The Cambridge Structural Database. Acta Crystallographica Section B Structural Science, Crystal Engineering and Materials 72:171-179. DOI: $10.1107 /$ S2052520616003954

24. Guillot B, Enrique E, Huder L, Jelsch C (2014) MoProViewer: a tool to study proteins from a charge density science perspective. Acta Crystallographica Section A 70 (a1):C279. doi:doi:10.1107/S2053273314097204

25. Jelsch C, Soudani S, Ben Nasr C (2015) Likelihood of atom-atom contacts in crystal structures of halogenated organic compounds. IUCrJ 2:327-340. doi:10.1107/s2052252515003255

26. Thomas IR, Bruno IJ, Cole JC, Macrae CF, Pidcock E, Wood PA (2010) WebCSD: the online portal to the Cambridge Structural Database. Journal of Applied Crystallography 43:362-366. doi:10.1107/s0021889810000452 
27. Akinboye ES, Butcher RJ, Brandy Y, Adesiyun TA, Bakare O (2009) N-(3-Bromo-1,4-dioxo-1,4dihydro-2-naphthyl)-2-chloro-N-(2-chlorobenzoyl)-benzamide. Acta Crystallographica Section EStructure Reports Online 65:024-U1485. doi:10.1107/s1600536808039214

28. Akinboye ES, Butcher RJ, Wright DA, Brandy Y, Bakare O (2009) N-(3-Bromo-1,4-dioxo-1,4dihydro-2-naphthyl)-4-fluoro-N-(4-fluorobenzoyl)benzamide. Acta Crystallographica Section EStructure Reports Online 65:0277-U1759. doi:10.1107/s1600536809000117

29. Moriuchi T, Ikeda I, Hirao T (1995) Synthesis and molecular-structure of the novel imide-bridged 3-ferrocenophane. Organometallics 14 (7):3578-3580. doi:10.1021/om00007a069

30. Moriuchi T, Bandoh S, Miyaji Y, Hirao T (2000) A novel heterobimetallic complex composed of the imide-bridged 3-ferrocenophane and the tridentate palladium(II) complex. Journal of Organometallic Chemistry 599 (2):135-142. doi:10.1016/s0022-328x(99)00748-2

31. Moriuchi T, Hirao T (2007) Imide-bridged diferrocene for protonation-controlled regulation of electronic communication. Tetrahedron Letters 48 (29):5099-5101. doi:10.1016/j.tetlet.2007.05.095

32. Valkonen A, Kolehmainen E, Osmialowski B (2011) N-2,N-2,N-6,N-6-Tetrakis (2,3,4,5,6pentafluorobenzoyl)pyridine-2,6-diamine. Acta Crystallographica Section E-Structure Reports Online 67:03429-U1660. doi:10.1107/s1600536811048768 


\section{ELECTRONIC SUPPLEMENTARY INFORMATION}

\section{Aggregation in isomeric imides: analysis of the weak interactions in six $\mathrm{N}$-(benzoyl)- $\mathrm{N}$-(2-pyridyl)benzamides.}

Pavle Mocilac, ${ }^{\text {a }}$ Mark Farrell, ${ }^{a}$ Alan J. Lough, ${ }^{b}$ Christian Jelsch $^{c}$ and John F. Gallagher ${ }^{a, c^{*}}$

${ }^{a}$ School of Chemical Sciences, Dublin City University, Dublin 9, Ireland,

${ }^{b}$ Department of Chemistry, 80 St. George Street, University of Toronto, Toronto, M5S 3H6, ON, Canada

'CRM2, CNRS, Faculté des Sciences et Technologies, Université de Lorraine, BP, 70239, Boulevard des Aiguellettes, 54506 Vandoeuvre-dès-Nancy, France

* Corresponding author: Dr. John F. Gallagher

E-mail: john.gallagher@dcu.ie

Telephone: +353-1-7005114

Fax: $\quad+353-1-7005503$ 


\section{Table of contents:}

$\begin{array}{lr}\text { Reaction and conformation schemes } & \mathbf{3}\end{array}$

$\begin{array}{lr}\text { Synthesis and comments } & \mathbf{4}\end{array}$

$\begin{array}{lr}\text { Spectral Data } & 6\end{array}$

$\begin{array}{ll}\text { Supplementary Table on crystal packing } & 19\end{array}$

$\begin{array}{ll}\text { Overlay of the Mxod molecular structure pairs. } & \mathbf{2 0}\end{array}$

Comparison of selected torsion/dihedral angles in Mxod (IV)-(VI) $\left(\AA,^{\circ}{ }^{\circ}\right.$.

Central Imide group Interplanar angles and deviations from planar geometry $\quad 23$ 


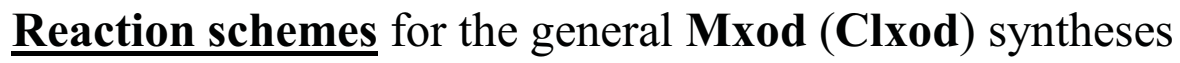<smiles>COc1ccccc1C(=O)Nc1ccccn1</smiles>

A scheme showing the open Mpod (Mmod, Clxod) structures with Mood.

Mpod (as depicted below), Mmod

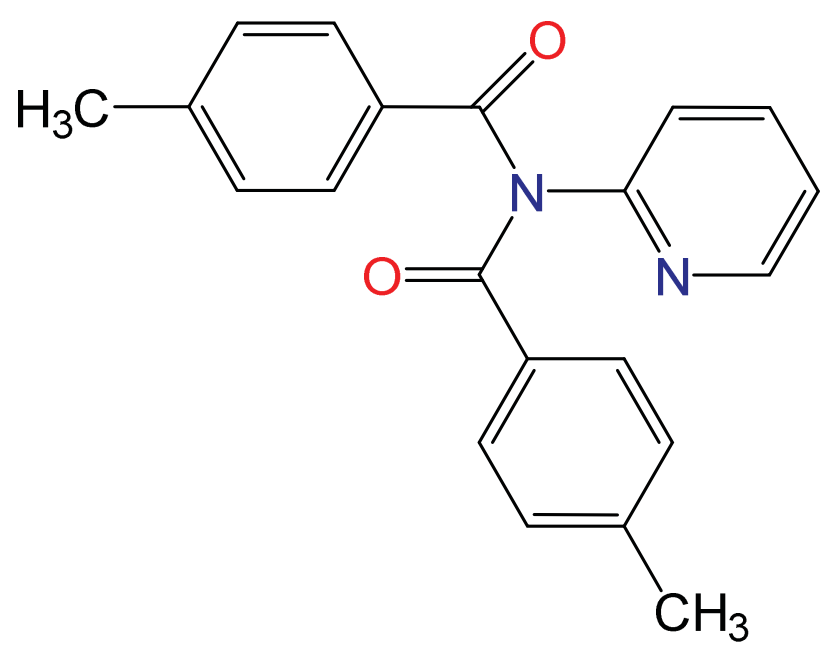

Mood

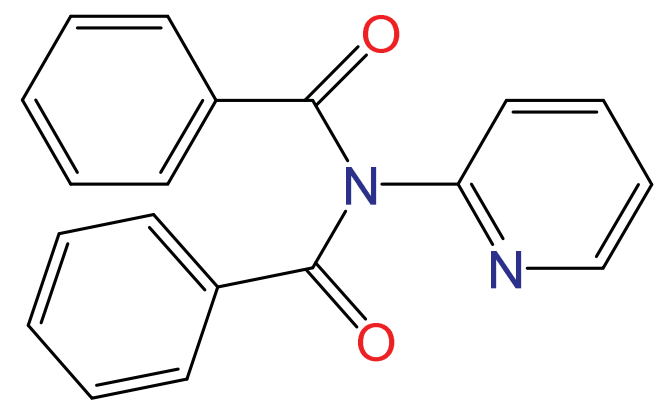




\section{Mxod synthesis (similar to the Clxod syntheses):}

The three Mpod, Mmod and Mood compounds (IV) - (VI) were prepared as follows:

Classical Schotten-Baumann reactions with 2-aminopyridine and the 4-, 3- or 2-toluoyl chlorides were used. Reactions were performed in anhydrous conditions in $\mathrm{CH}_{2} \mathrm{Cl}_{2}$ (under $\mathrm{N}_{2}$ ), initially at $5^{\circ} \mathrm{C}$ and then at room temperature. The 2-aminopyridine $(0.9411 \mathrm{~g}, 10.0$ $\mathrm{mmol}$ ) was added to a $250 \mathrm{ml}$ flask placed on an ice bath with stirring: then, $30 \mathrm{ml}$ of solvent $\left(\mathrm{CH}_{2} \mathrm{Cl}_{2}\right)$ was added to the flask, followed by addition of $\mathrm{Et}_{3} \mathrm{~N}(3 \mathrm{ml}, 21.52 \mathrm{mmol})$. Finally, the 4-, 3- or 2-toluoyl chlorides ( $c a .3 \mathrm{ml}, 22.0 \mathrm{mmol}$ ) were added in excess directly into the respective solution mixtures. The reaction mixture was allowed to warm to room temperature and stirred overnight. The organic reaction phase was washed with $20 \mathrm{ml}$ of $\mathrm{KHCO}_{3}(0.1 \mathrm{M})$ solution ca. 3-5 times and dried with anhydrous $\mathrm{MgSO}_{4}$. The solvent was evaporated under vacuum and the saturated solution was placed on ice and crystallization was induced and the resulting product dried overnight.

For the Mmod and Mood products, the product contains small amounts of Mmo and Moo, (Mocilac et al., 2010) therefore, column chromatography was used to obtain pure compounds of Mmod and Mood using $\mathrm{CHCl}_{3}$, ethyl acetate and cyclohexane (4:2:1) as the mobile phase and silica as stationary phase. The Mmod and Mood were crystallised from ethyl acetate or cyclohexane (Mmod/Mood). For Mpod, the product was highly crystalline and sparingly soluble in $\mathrm{CHCl}_{3}$. Therefore, no chromatography was needed; the crude crystalline product was just washed with cold $\mathrm{CHCl}_{3}$ on a Büchner's funnel and allowed to dry. The resulting white crystals were pure Mpod and no further purification was needed.

\section{Discussion and unusual isolation of Clomd:}

The imide (2:1) product was originally obtained in 4 cases as the Clpod, Clmod, Clood triad as well as the unusual Clomd compound. The three Clxod crystal structures are as expected and are presented herein. The formation of the Clxod triad product was expected for the ortho benzamide ( $\mathbf{C l x o}$ ) series of compounds and due to 2 main factors:

(a) The maximisation of the electronic effects of the aromatic $\mathrm{N}$ atom (electron withdrawing) in the ortho position.

(b) The proximity of the nitrogen to the hydrogen of the $\mathrm{N}-\mathrm{H}$ allows for an intramolecular $\mathrm{H}$-bonding interaction between the aromatic pyridine ring $\mathrm{N}$ and the $\mathrm{N}-\mathrm{H}$ hydrogen. This interaction weakens the $\mathrm{N}-\mathrm{H}$ bond, therefore making it easier to remove the hydrogen (thus reacting with the chlorobenzoyl chloride) leading to the formation of the $2: 1$ product.

The reasons stated above however do not apply in the Clomd case as:

(c) The electronic effect of the pyridine $\mathrm{N}$ atom is far from optimal in the meta position as compared to the ortho case for the Clxod series.

(d) The pyridine ring $\mathrm{N}$ atom (in the meta-position) would have a much smaller effect on the hydrogen (with respect to $\mathrm{H}$-bonding) than for the ortho-cases. 
Therefore a different interaction/factor must contribute to the formation of the 2:1 product in the Clomd case. It is believed that the proximity of the ortho-chlorine to the $\mathrm{N}-\mathrm{H}$ hydrogen creates an induced dipole between the species ( $\delta$-ve on chlorine atom and $\delta+v e$ on the hydrogen atom). This induced dipole would weaken the $\mathrm{N}-\mathrm{H}$ bond and therefore increase the probability of the 2:1 product forming (as seen).

The fact that the Clop (chlorine also in the ortho position) reaction did not produce a 2:1 product shows that the induced dipole effect alone is not sufficient for 2:1 formation, as it would also be obtained in this reaction if this was the case. It therefore suggests that the nitrogen of the pyridine ring in Clom (meta-nitrogen) influences (electronically) the formation of the 2:1 product.

\section{Melting point trends for Clxod}

The 2:1 compounds have a similar trend observed with Clpod $>$ Clmod $>$ Clood, this is a similar trend to that observed for the 1:1 compounds (Clpo $>\mathrm{Clmo}>\mathrm{Cloo}$ ). The melting point of the 2:1 compounds was generally higher than that of the respective molecule with Clpod > Clpo, Clmo > Clmod and Clood >Cloo, this however was not true for Clomd (Clom > Clomd). The trend of higher melting points for the 2:1 compounds could be explained by increased molecular weight, the addition of more aromatic rings thus increasing the possibility of $\pi-\pi$ stacking interactions thus increasing the melting point. The fact that Clomd has a lower melting point could possibly be caused by a less efficient crystal packing compared to the 1:1 compound (Clom). 


\section{Clomd: 2-Chloro- $N$-(2-chlorobenzoyl)- $N$-(3)- pyridinyl)benzamide}<smiles>O=C(c1ccccc1Cl)N(C(=O)c1ccccc1Cl)c1cccnc1</smiles><smiles>O=C(c1ccccc1Cl)N(C(=O)c1ccccc1Cl)c1ccccc1</smiles>

Reaction Notes: The product obtained as a result of the reaction of 2-chlorobenzoylchloride with 3-aminopyridine (the Clom reaction). Description: Brown powder.

Notes: It was unexpected for this product to be obtained from the reaction. It was seen as an impurity spot in the TLC of the Clom reaction. The product was identified using NMR data and knowledge of similar imides.

TLC: Mobile phase used: Chloroform:Ethyl Acetate (1:1). Clomd is fraction $1\left(R_{f}=0.41\right)$.

Clomd: $\left(0.5732 \mathrm{~g}\right.$, yield $=17.5 \%$; m.p. $\left.=114.4-116.7^{\circ} \mathrm{C}\right) ; \mathrm{IR}$ (thin layer); $3012(\mathrm{~s}), 1706(\mathrm{~s})$, $1672(\mathrm{~s}), 1592(\mathrm{~m}), 1477(\mathrm{~m}), 1436(\mathrm{~s}), 1424(\mathrm{~s}), 1345(\mathrm{~m}), 1274(\mathrm{~m}), 1216(\mathrm{~s}), 1144$ (m), $756(\mathrm{~s})$;

${ }^{1} \mathrm{H}-\mathrm{NMR}\left(\mathrm{CDCl}_{3}\right)$ 8: $7.14(2 \mathrm{H}, \mathrm{m}), 7.19(4 \mathrm{H}, \mathrm{m}), 7.30(1 \mathrm{H}, \mathrm{q}), 7.41(2 \mathrm{H}, \mathrm{d}), 7.71(1 \mathrm{H}, \mathrm{d})$, $8.49(1 \mathrm{H}, \mathrm{d}), 8.58(1 \mathrm{H}, \mathrm{d})$.

Notes: Doublet at 8.58ppm looks like a singlet experiencing long range coupling.

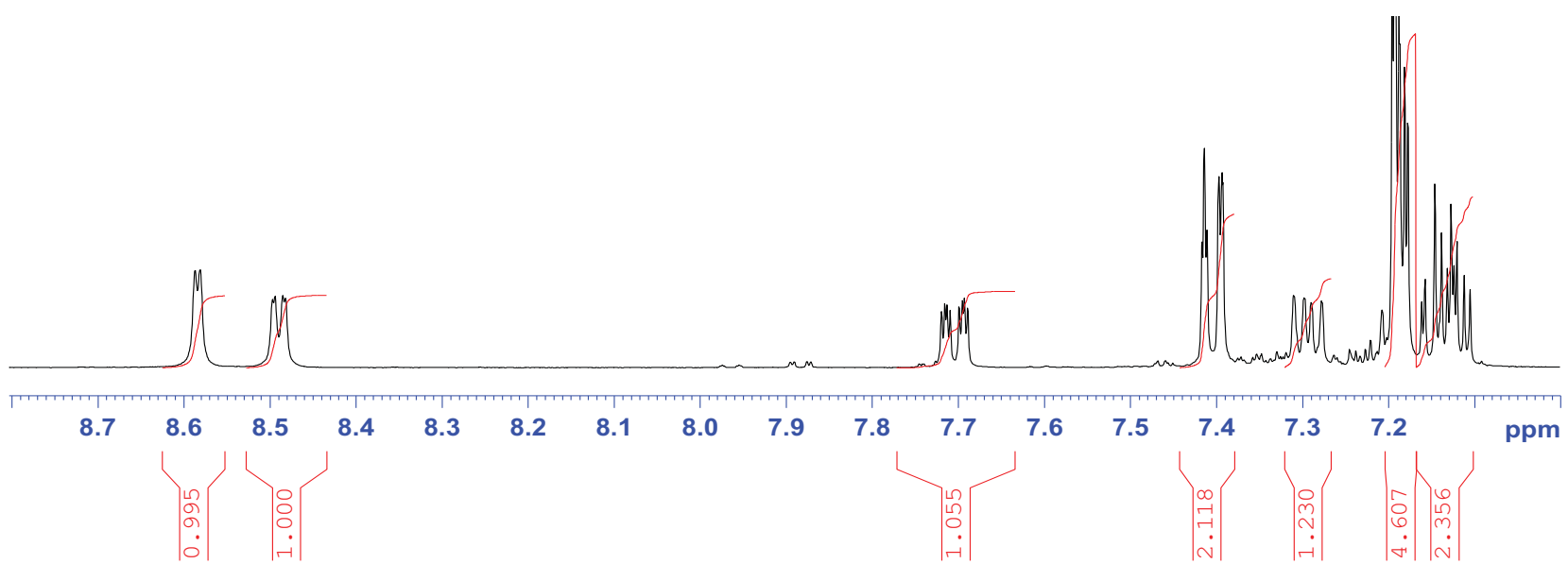




\section{Clpod: 4-Chloro-N-(4-chlorobenzoyl)-N-(2-pyridinyl)benzamide}<smiles>O=C(c1ccc(Cl)cc1)N(C(=O)c1ccc(Cl)cc1)c1ccccn1</smiles><smiles></smiles>

Description: Light yellow fine powder

TLC: Mobile Phase used: Chloroform: Ethyl Acetate(1:1)

Notes: No impurity spots were obtained following isolation of this product.

Clpod: $\quad\left(0.7464 \mathrm{~g}\right.$, yield $\left.=22.8 \%, \mathrm{~m} . \mathrm{p} .=171.5-175.5^{\circ} \mathrm{C}\right)$; IR(thin layer): $3058(\mathrm{w}), 2921(\mathrm{w})$, $2356(w), 1792(w / m), 1693(\mathrm{~s}), 1589(\mathrm{~s}), 1485(\mathrm{~m}), 1436(\mathrm{~s}), 1397(\mathrm{~m}), 1288(\mathrm{~s})$, $1244(\mathrm{~s}), 1090(\mathrm{~s}), 1014(\mathrm{~s}), 866(\mathrm{~s}), 751$ (s);

${ }^{1} \mathrm{H}-\mathrm{NMR}\left(\mathrm{CDCl}_{3}\right)$ 8: $7.13(1 \mathrm{H}, \mathrm{q}), 7.20(1 \mathrm{H}, \mathrm{m}), 7.27(4 \mathrm{H}, \mathrm{d}), 7.63(4 \mathrm{H}, \mathrm{d}), 7.67(1 \mathrm{H}$, t), 8.33 .

Notes: The peak at 7.20ppm has a reported integration of 1 , however as seen on the spectra the integration is in fact 4 , this is due to the overlap of the peak with the chloroform

\section{${ }^{1}$ H-NMR Spectra:}

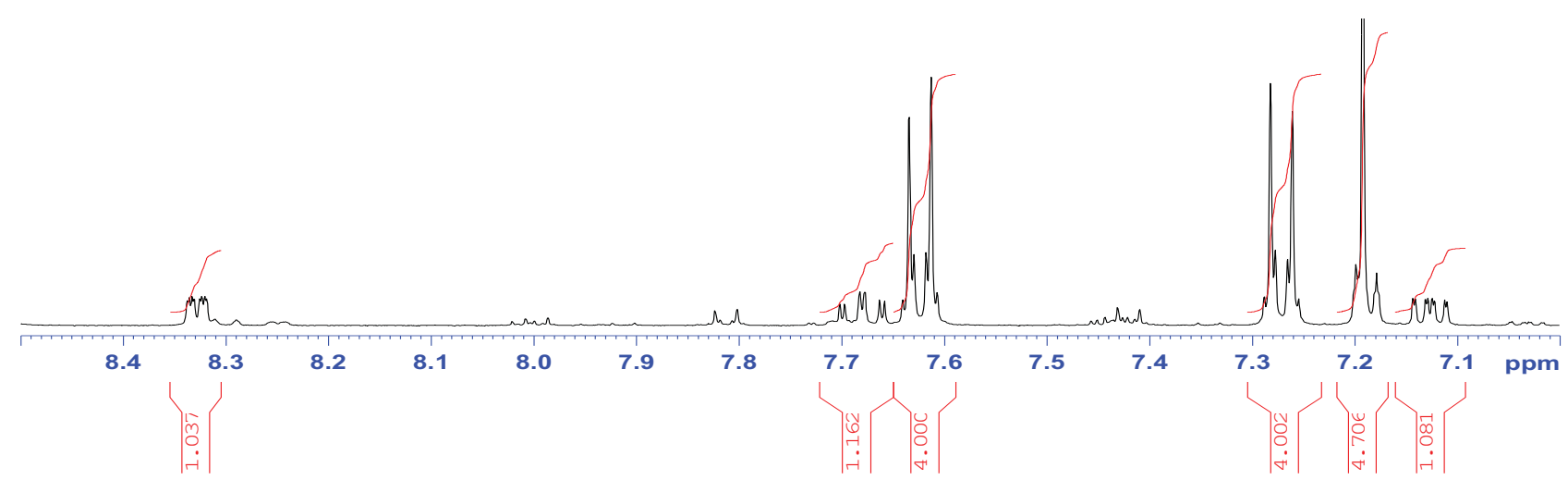


Clmod: 3-Chloro-N-(3-chlorobenzoyl)-N-(2-pyridinyl)benzamide<smiles>O=C(c1cccc(Cl)c1)N(C(=O)c1cccc(Cl)c1)c1ccccn1</smiles><smiles>O=C(c1cccc(Cl)c1)N(C(=O)c1cccc(Cl)c1)c1ccccn1</smiles>

Reaction Notes: As seen for Clmo.

Description: Light yellow crystals.

TLC: Mobile Phase used: Chloroform:Ethyl Acetate(2:1)

Notes: No impurity spots were observed on the Silica plate.

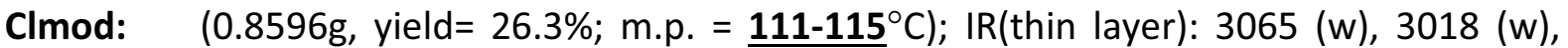
1795 (s), 1695 (s), 1590 (s), 1569 (s), 1469 (s), 1416 (m), 1290 (s), 1233 (s), 1143 $(\mathrm{m}), 1044(\mathrm{~m}), 886(\mathrm{w})$;

${ }^{1} \mathrm{H}-\mathrm{NMR}\left(\mathrm{CDCl}_{3}\right)$ 8:7.23 (1H, q), $7.30(3 \mathrm{H}, \mathrm{m}), 7.47(1 \mathrm{H}, \mathrm{d}), 7.52(1 \mathrm{H}, \mathrm{t}), 7.63(2 \mathrm{H}$, d), $7.78(3 \mathrm{H}, \mathrm{m}), 8.42(1 \mathrm{H}, \mathrm{d})$.

Notes: Peak at 7.30ppm has integration of 4 however this includes chloroform peak therefore the actual integration is 3. The peak at 7.78ppm consists of 3 peaks that overlap therefore are integrated as one.

\section{${ }^{1}$ H-NMR Spectra:}

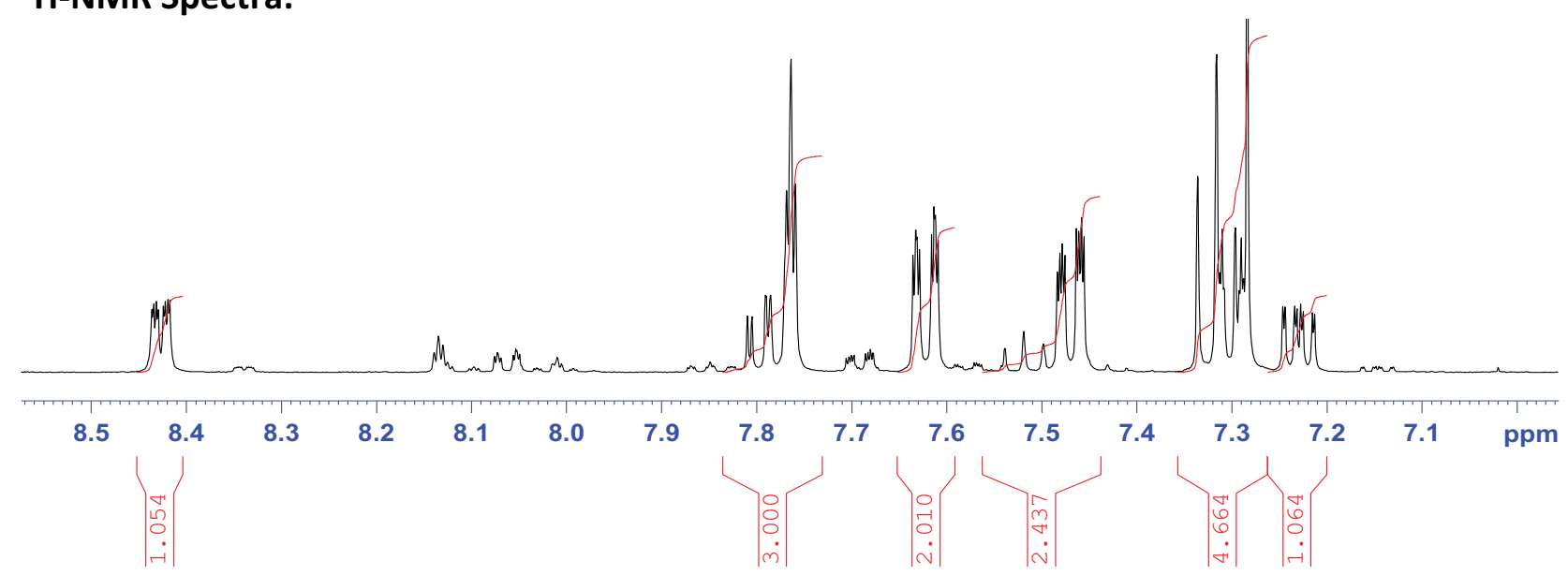




\section{Clood: 2-Chloro- $\mathrm{N}$-(2-chlorobenzoyl)-N-(2-pyridinyl)benzamide}<smiles>O=C(OCc1ccccc1)N(C(=O)c1ccccc1Cl)c1ccccn1</smiles>

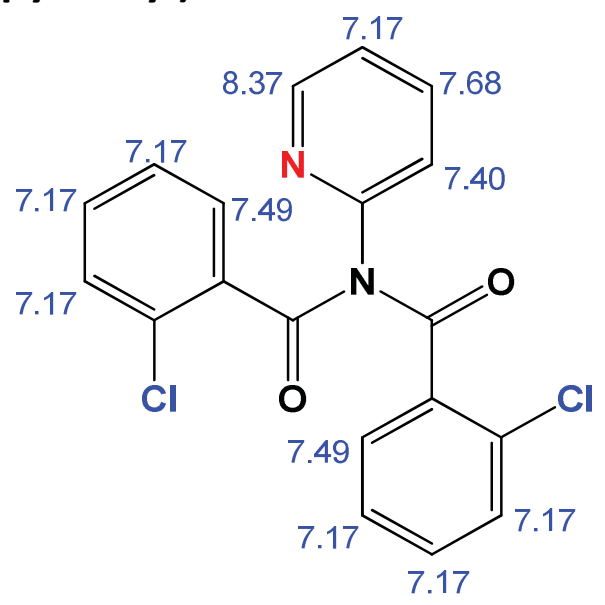

Description: Light green/off-white colour crystals.

Notes: The product was extremely hard to crystallise. It was obtained as a slightly green colour gel after treatment on the rotary evaporator.

TLC: Mobile Phase used: Chloroform:Ethyl Acetate(2:1)

Clood: $\quad\left(0.8037 \mathrm{~g}\right.$, yield $=24.6 \%$; m.p. $\left.=113.7-117.4^{\circ} \mathrm{C}\right) ; \mathrm{IR}$ (thin layer): $3063(\mathrm{~m}), 3019(\mathrm{~m})$, 2362 (w), 1699 (s), 1667 (s), 1468 (s), 1436 (s), 1244 (s), 1145 (s), 1090 (m), $11052(\mathrm{~s}), 997(\mathrm{~m}), 855(\mathrm{~m}), 751(\mathrm{~s})$;

${ }^{1} \mathrm{H}-\mathrm{NMR}\left(\mathrm{CDCl}_{3}\right)$ 8: $7.17(7 \mathrm{H}, \mathrm{m}), 7.41(1 \mathrm{H}, \mathrm{d}), 7.49(2 \mathrm{H}, \mathrm{d}), 7.68(1 \mathrm{H}, \mathrm{t}), 8.37(1 \mathrm{H}$, d).

Notes: The peak at 7.17ppm is reported as having an integration of $7 \mathrm{H}$, in the spectra the integration is seen as 8 this is due to the presence of the solvent peak of chloroform. It is also observed that the peak at $8.37 \mathrm{ppm}$ and $7.68 \mathrm{ppm}$ experience long range coupling(seen by the minor splitting of the peaks).

\section{${ }^{1}$ H-NMR Spectra:}

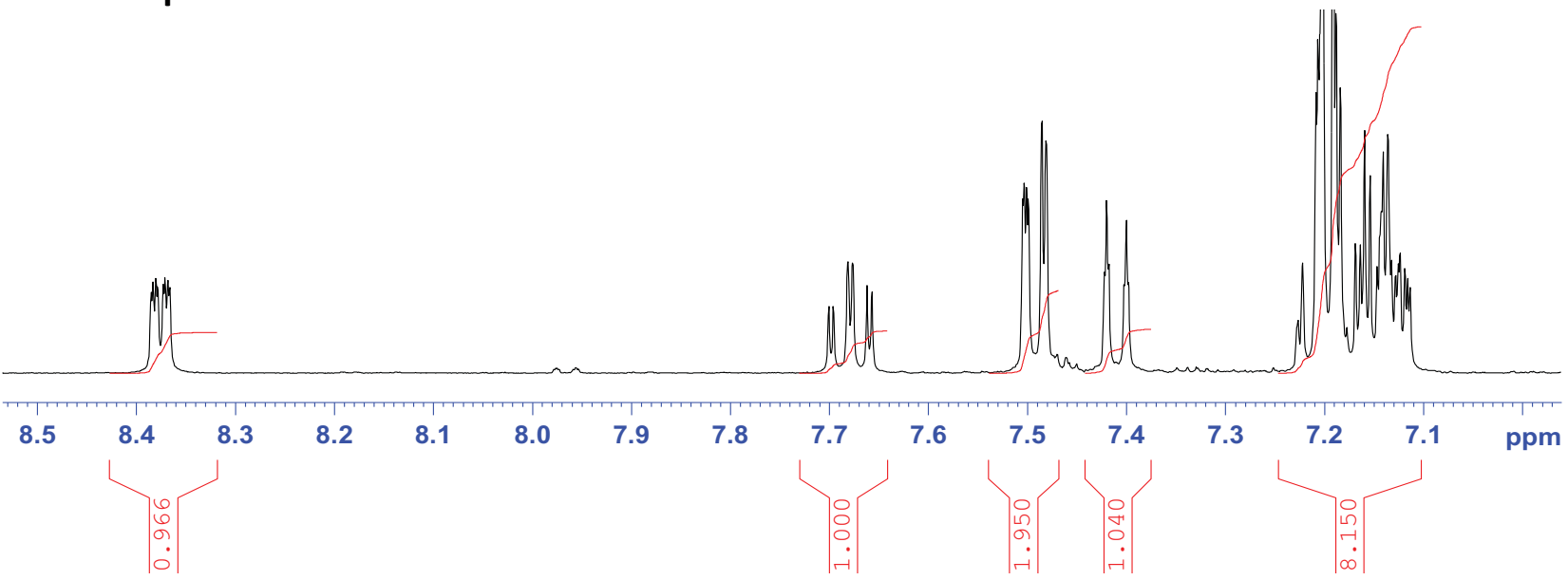


Mpod: 4-methyl-N-(4-methylbenzoyl)- $N$-(2-pyridinyl)benzamide<smiles>Cc1ccc(C(=O)N(C(=O)c2ccc(C)cc2)c2ccccn2)cc1</smiles><smiles></smiles>

\section{${ }^{1} \mathrm{H}$ NMR in DMSO-d 6,600 Mhz:}

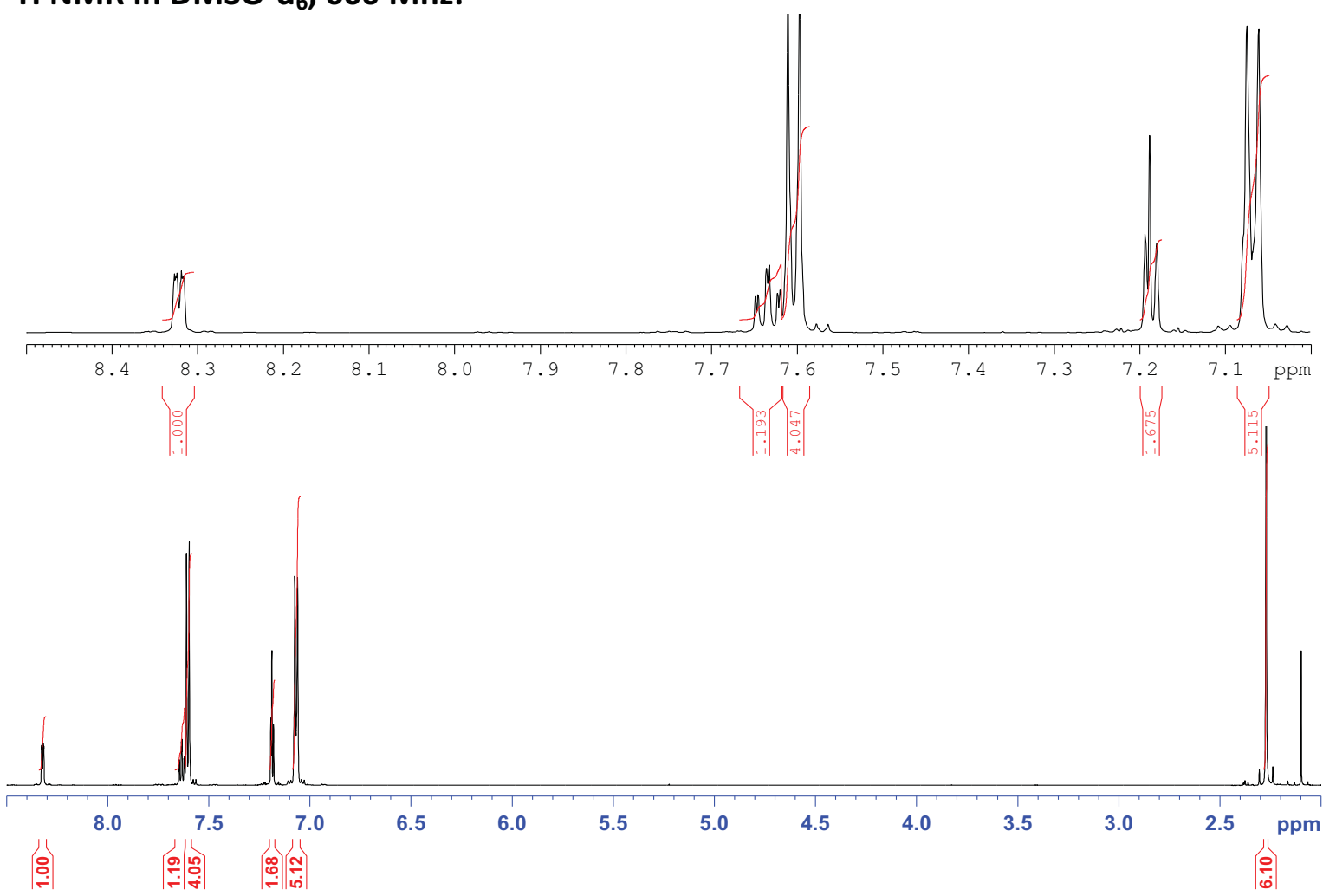

${ }^{1} \mathrm{H}$ NMR $\left(600 \mathrm{Mhz}, \mathrm{DMSO}-\mathrm{d}_{6}\right) \delta 2.32,(6 \mathrm{H}, \mathrm{s}, 2 \times \mathrm{H} 17 \mathrm{~A} / \mathrm{B} / \mathrm{C}), 7.24\left(4 \mathrm{H}, \mathrm{d}^{3} \mathrm{~J}=8.0,2 \times \mathrm{H} 13, \mathrm{H} 15\right), 7.27\left(1 \mathrm{H}, \mathrm{ddd},{ }^{3} \mathrm{~J}\right.$ $\left.=7.4,{ }^{4} \mathrm{~J}=4.9,{ }^{4} \mathrm{~J}=1.0\right), 7.53\left(1 \mathrm{H}, \mathrm{dt},{ }^{3} \mathrm{~J}=8.0,{ }^{4} \mathrm{~J}=1.0 \mathrm{H} 22\right), 7.64\left(4 \mathrm{H}, \mathrm{dd},{ }^{3} \mathrm{~J}=6.6,{ }^{4} \mathrm{~J}=1.6,2 \times \mathrm{H} 12, \mathrm{H} 16\right), 7.89(1 \mathrm{H}$, $\left.\mathrm{td},{ }^{3} J=6.6,{ }^{4} \mathrm{~J}=1.6, \mathrm{H} 23\right), 8.29\left(1 \mathrm{H}, \mathrm{ddd},{ }^{3} \mathrm{~J}=4.8,{ }^{4} \mathrm{~J}=1.8,{ }^{5} \mathrm{~J}=0.8, \mathrm{H} 25\right)$; 


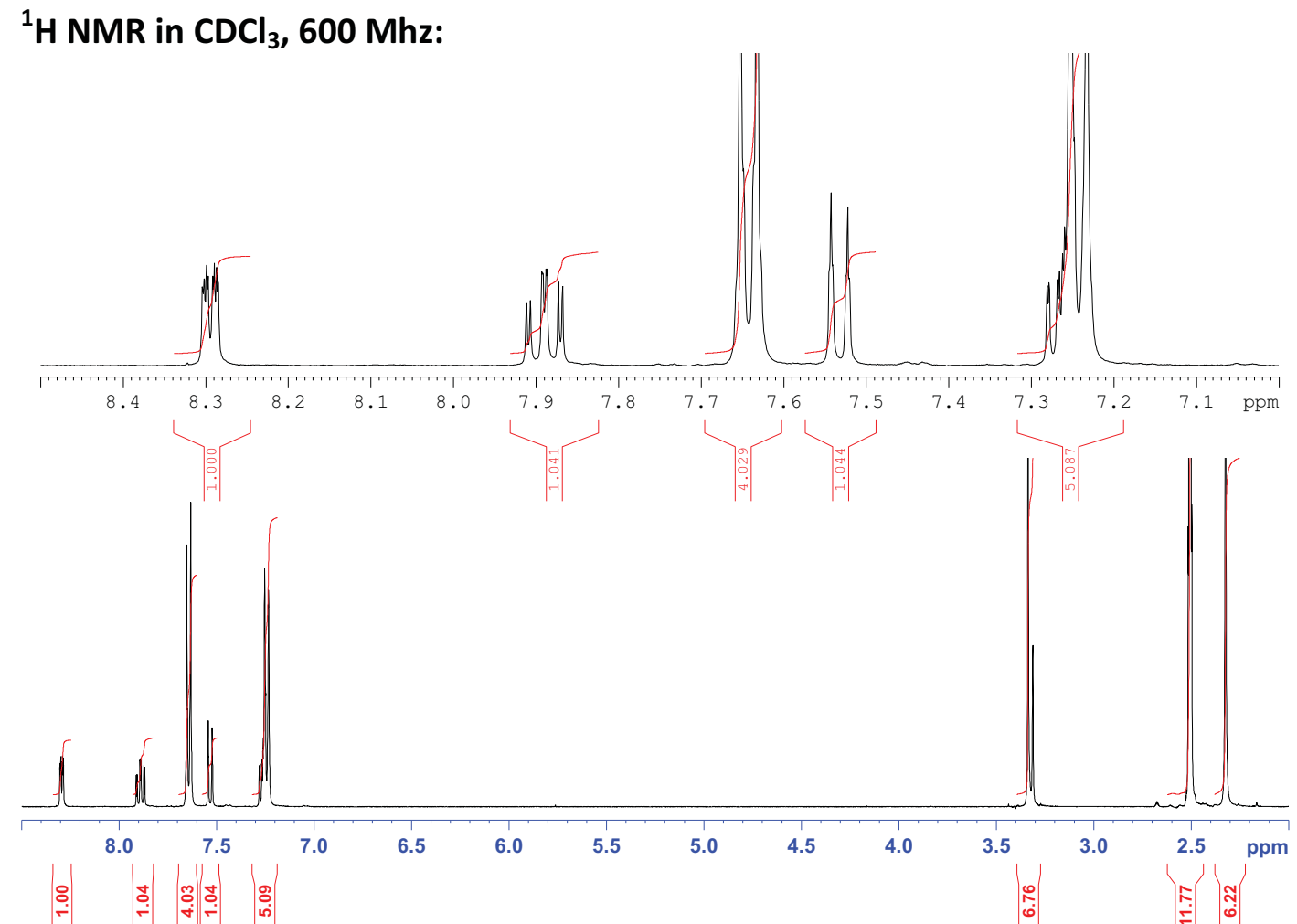

${ }^{1} \mathrm{H}$ NMR $\left(400 \mathrm{MHz}, \mathrm{CDCl}_{3}\right) \delta 2.27(6 \mathrm{H}, \mathrm{s}, 2 \times \mathrm{H} 17 \mathrm{~A} / \mathrm{B} / \mathrm{C}), 7.07\left(4 \mathrm{H}, \mathrm{d},{ }^{3} \mathrm{~J}=8.0, \mathrm{H} 24,2 \times \mathrm{H} 13, \mathrm{H} 15\right), 7.19(1 \mathrm{H}, \mathrm{d}$, $\left.{ }^{3} \mathrm{~J}=8.0, \mathrm{H} 22\right), 7.60\left(4 \mathrm{H}, \mathrm{dd},{ }^{3} \mathrm{~J}=6.7,{ }^{4} \mathrm{~J}=1.6,2 \times \mathrm{H} 12, \mathrm{H} 16\right), 7.63\left(1 \mathrm{H}, \mathrm{td},{ }^{3} \mathrm{~J}=7.8,{ }^{4} \mathrm{~J}=1.8, \mathrm{H} 23\right), 8.32\left(1 \mathrm{H}, \mathrm{ddd},{ }^{3} \mathrm{~J}=\right.$ $\left.4.8,{ }^{4} \mathrm{~J}=1.8,{ }^{5} \mathrm{~J}=0.8, \mathrm{H} 25\right)$;

\section{${ }^{13} \mathrm{C}$ NMR in DMSO-d $6,600 \mathrm{Mhz}$ :}
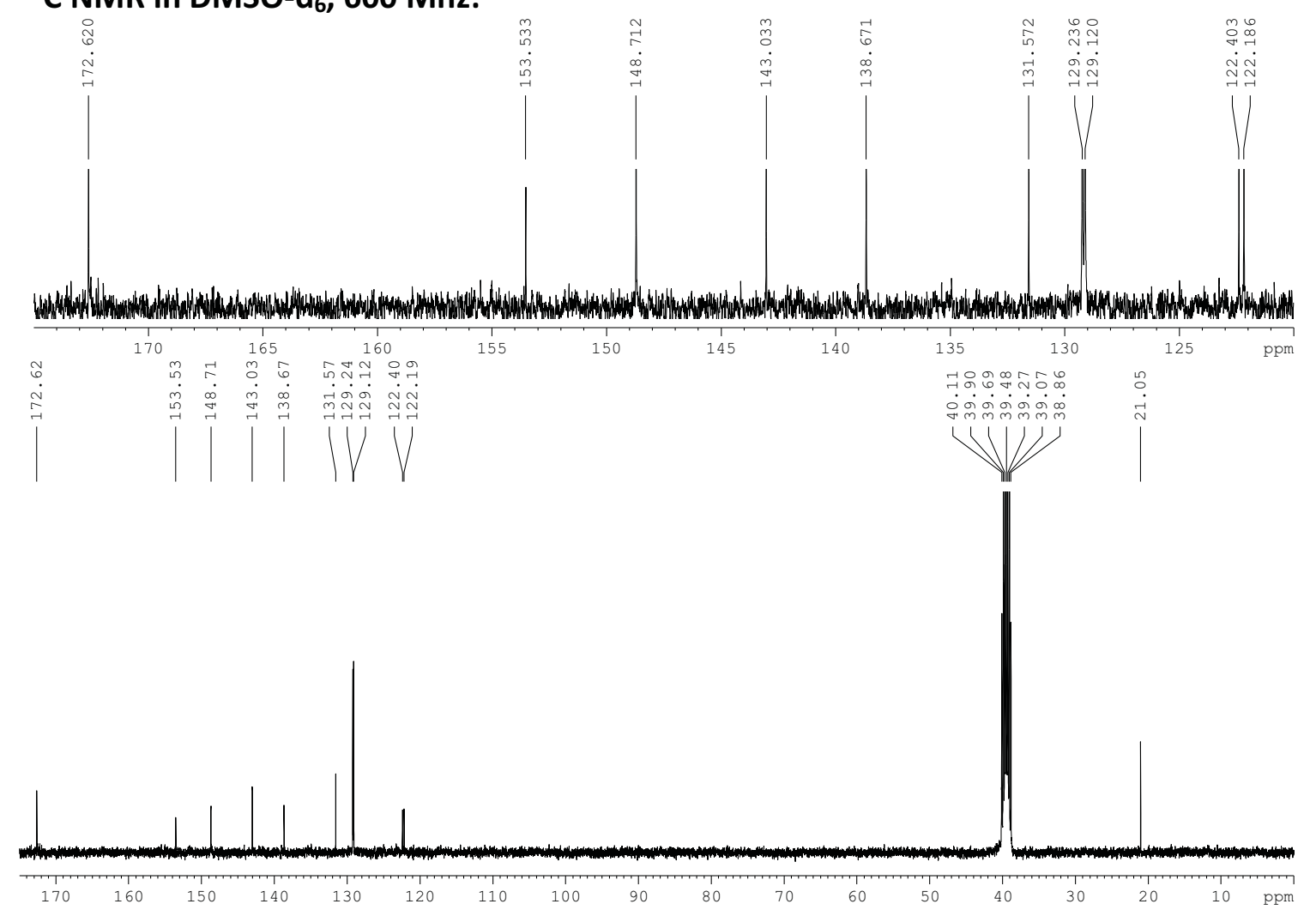

${ }^{13}$ C NMR (DMSO-d 6 ) $\delta 21.04,122.19,122.40,129.12,129.23,131.57,138.67,143.03,148.71,153.53,172.62$. 


\section{FT-IR ( $\mathrm{KBr}$ disc):}

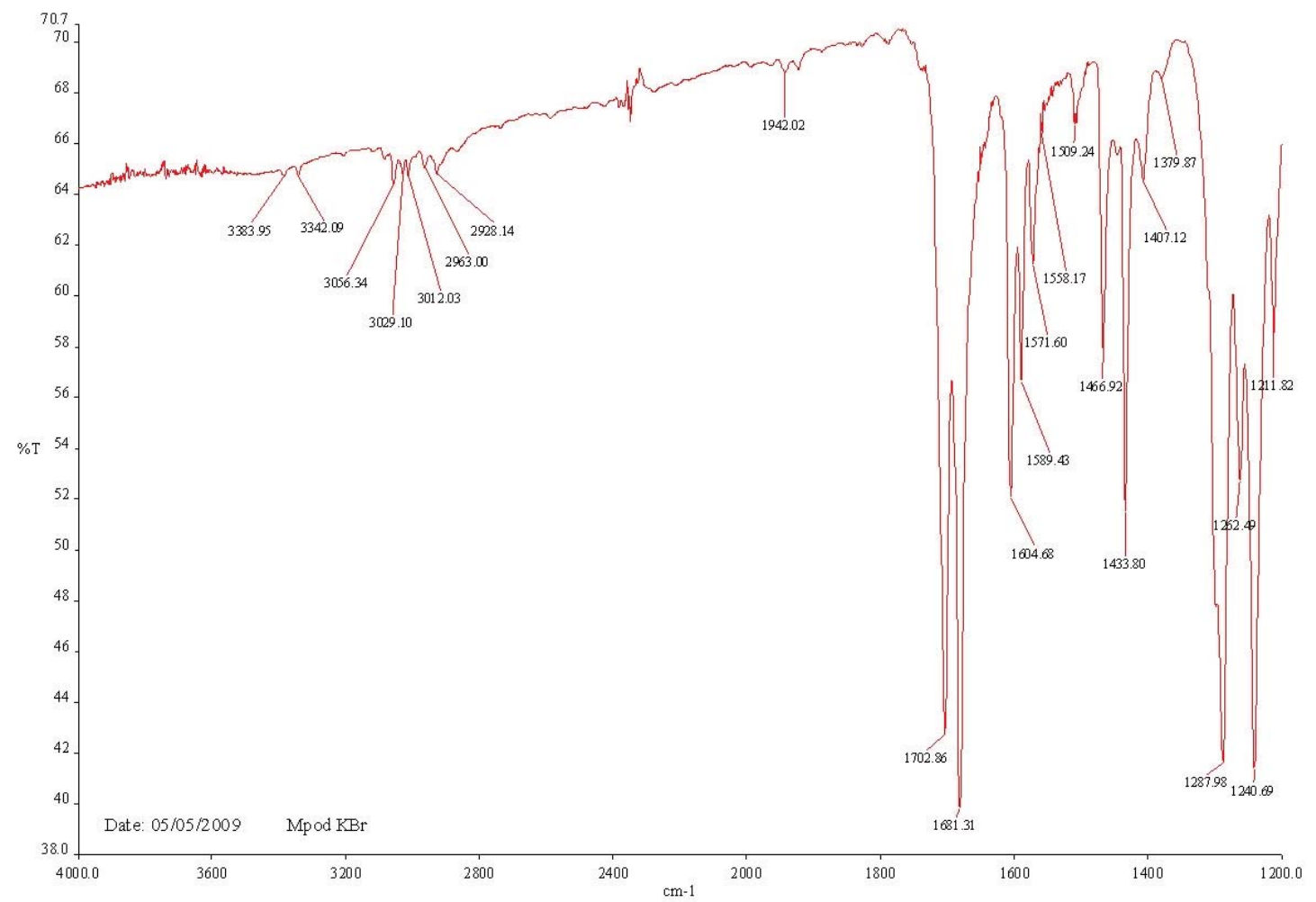

IR (KBr disc): 3056 (w), 3029 (w), 2963 (w), 2928 (w), 1703 (s), 1681 (s), 1605 (s), $1589(\mathrm{~m}), 1572(\mathrm{~m}), 1509(\mathrm{w})$, $1467(\mathrm{~m}), 1434(\mathrm{~s}), 1407(\mathrm{w})$; 
Mmod: 3-methyl-N-(3-methylbenzoyl)-N-(2-pyridinyl)benzamide<smiles>COC(C)(C)OC(=O)c1cccc(C)c1</smiles><smiles>Cc1cccc(C(=O)N(C(=O)c2cccc(C)c2)c2ccccn2)c1</smiles>

${ }^{1} \mathrm{H}$ NMR in DMSO-d 6,600 Mhz:

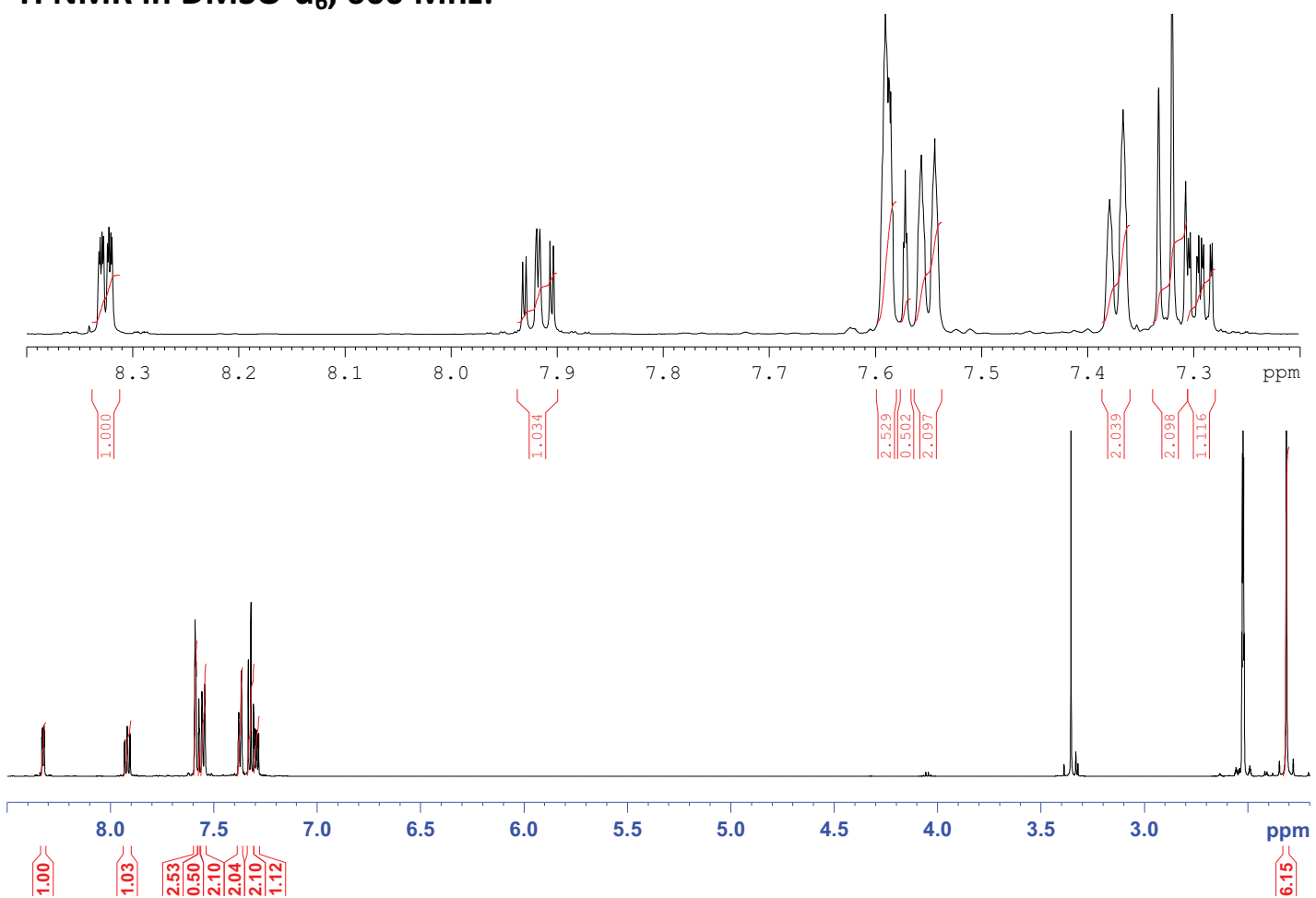

${ }^{1} \mathrm{H}$ NMR (DMSO-d 6 ) $\delta 2.31(6 \mathrm{H}, \mathrm{s}, 2 \times \mathrm{H} 17 \mathrm{~A} / \mathrm{B} / \mathrm{C}), 7.29\left(1 \mathrm{H}, \mathrm{ddd},{ }^{3} \mathrm{~J}=7.4,{ }^{4} \mathrm{~J}=4.9,{ }^{4} \mathrm{~J}=1.0, \mathrm{H} 24\right), 7.32\left(2 \mathrm{H}, \mathrm{t},{ }^{3} \mathrm{~J}=\right.$ 7.7, $2 \times \mathrm{H} 15), 7.37\left(2 \mathrm{H}, \mathrm{d}^{3} J=7.6,2 \times \mathrm{H} 14\right), 7.55\left(2 \mathrm{H}, \mathrm{d}^{3} \mathrm{~J}=7.5,2 \times \mathrm{H} 16\right), 7.58\left(1 \mathrm{H}, \mathrm{dt},{ }^{3} J=8.2,{ }^{4} J=0.9, \mathrm{H} 22\right), 7.59$ $(2 \mathrm{H}, \mathrm{s}, 2 \times \mathrm{H} 12), 7.92\left(1 \mathrm{H}, \mathrm{td},{ }^{3} \mathrm{~J}=7.8,{ }^{4} \mathrm{~J}=1.9, \mathrm{H} 23\right), 8.33\left(1 \mathrm{H}, \mathrm{ddd},{ }^{3} \mathrm{~J}=4.9,{ }^{4} \mathrm{~J}=1.9,{ }^{5} \mathrm{~J}=0.7, \mathrm{H} 25\right)$; 


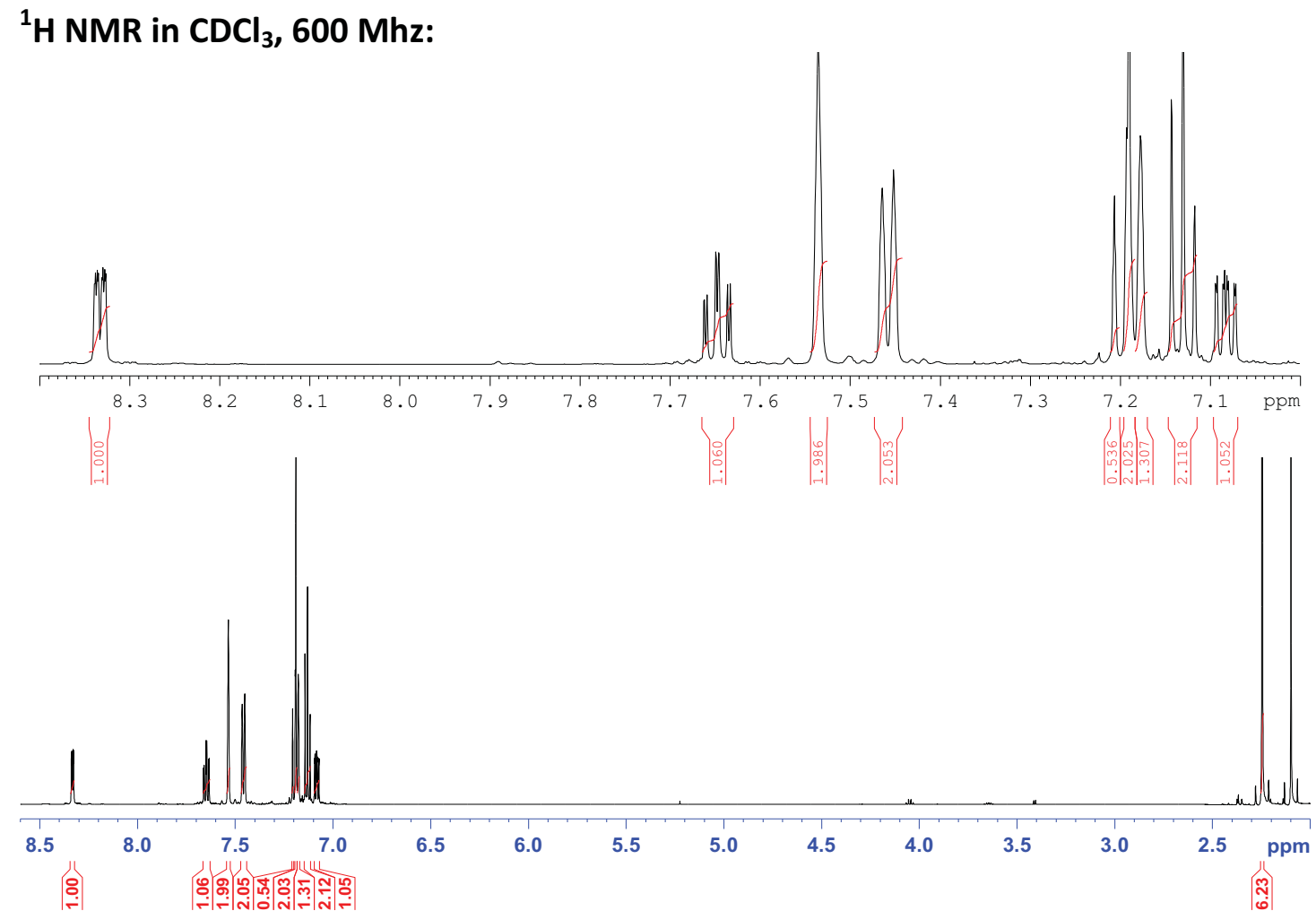

${ }^{1} \mathrm{H} \mathrm{NMR}\left(\mathrm{CDCl}_{3}\right) \delta 2.25(6 \mathrm{H}, \mathrm{s}, 2 \times \mathrm{H} 17 \mathrm{~A} / \mathrm{B} / \mathrm{C}), 7.08\left(1 \mathrm{H}, \mathrm{ddd},{ }^{3} \mathrm{~J}=7.5,{ }^{4} \mathrm{~J}=4.9,{ }^{4} \mathrm{~J}=1.0, \mathrm{H} 24\right), 7.13\left(2 \mathrm{H}, \mathrm{t},{ }^{3} \mathrm{~J}=7.7\right.$, $2 \times \mathrm{H} 15), 7.18\left(2 \mathrm{H}, \mathrm{d},{ }^{3} \mathrm{~J}=7.3,2 \times \mathrm{H} 14\right), 7.20\left(1 \mathrm{H}, \mathrm{dt},{ }^{3} \mathrm{~J}=8.0,{ }^{4} \mathrm{~J}=0.8, \mathrm{H} 22\right), 7.46\left(2 \mathrm{H}, \mathrm{d},{ }^{3} \mathrm{~J}=7.6,2 \times \mathrm{H} 16\right), 7.54(2 \mathrm{H}$, $\mathrm{s}, 2 \times \mathrm{H} 12), 7.65\left(1 \mathrm{H}, \mathrm{td},{ }^{3} \mathrm{~J}=7.8,{ }^{4} \mathrm{~J}=1.9, \mathrm{H} 23\right), 8.33\left(1 \mathrm{H}, \mathrm{ddd},{ }^{3} \mathrm{~J}=4.9,{ }^{4} \mathrm{~J}=1.8,{ }^{5} \mathrm{~J}=0.8, \mathrm{H} 25\right)$;

${ }^{13} \mathrm{C}-\mathrm{NMR}$ in DMSO-d $6,600 \mathrm{Mhz}$ :

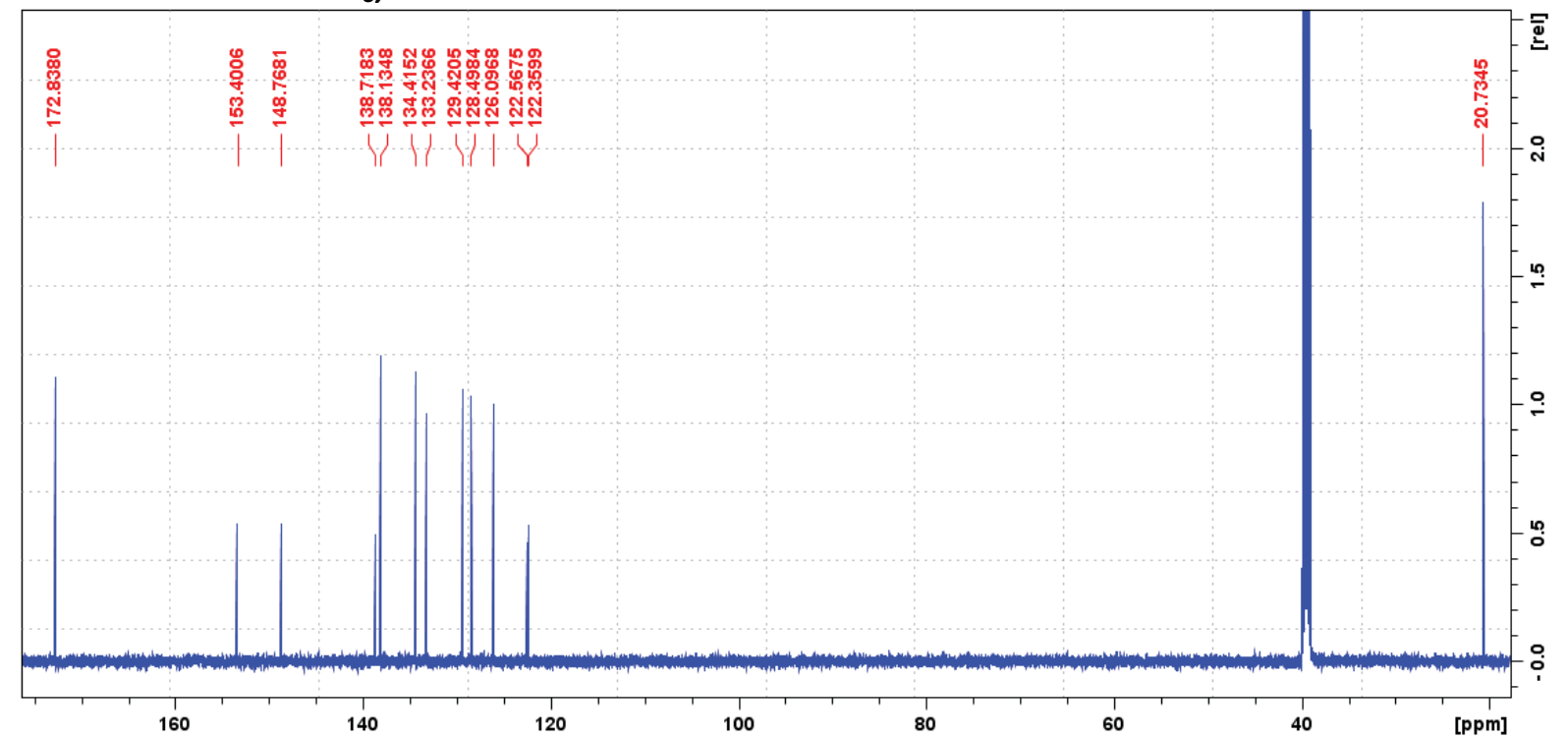

${ }^{13}{ }^{13}$ NMR (DMSO-d $)$ ) $\delta 20.73,122.36,122.57,126.09,128.50,129.42,133.24,134.41,138.13,138.72,148.77$, 153.40 172.84; 


\section{FT-IR ( $\mathrm{KBr}$ disc):}

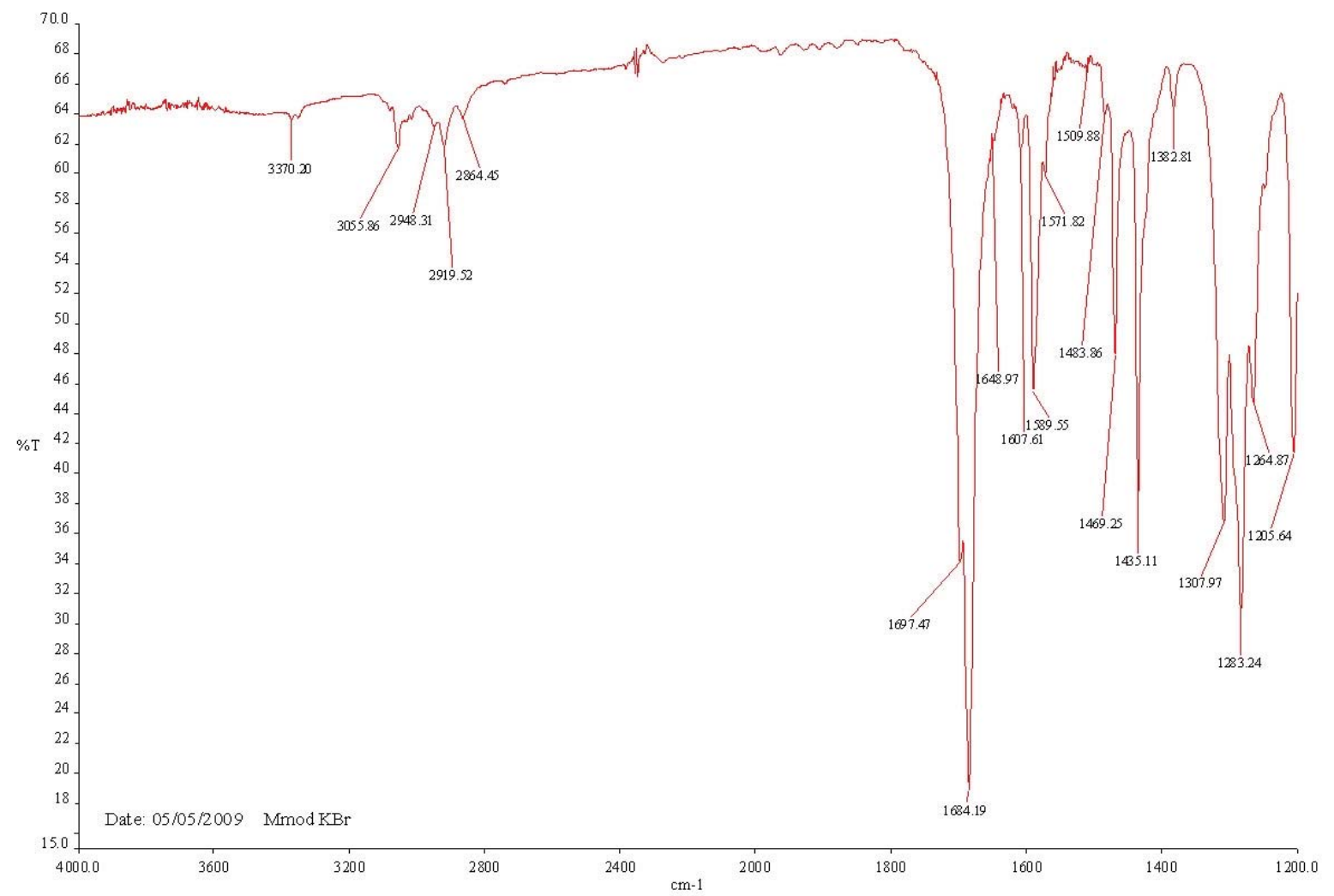

IR (KBr disc): 3370 (w), 3056 (w), 2948 (w), 2919 (w), 2864 (w), 1697 (s), 1684 (s), 1608 (w), $1590(\mathrm{~m}), 1484(w)$, $1469(\mathrm{~m}), 1435(\mathrm{~s})$; 
Mood: 2-methyl-N-(2-methylbenzoyl)-N-(2-pyridinyl)benzamide<smiles>COC(C)(C)COC(=O)c1ccccc1C</smiles><smiles>Cc1ccccc1C(=O)N(C(=O)c1ccccc1C)c1ncccc1Br</smiles>

${ }^{1} \mathrm{H}$ NMR in DMSO-d ${ }_{6}, 600 \mathrm{Mhz}$ :

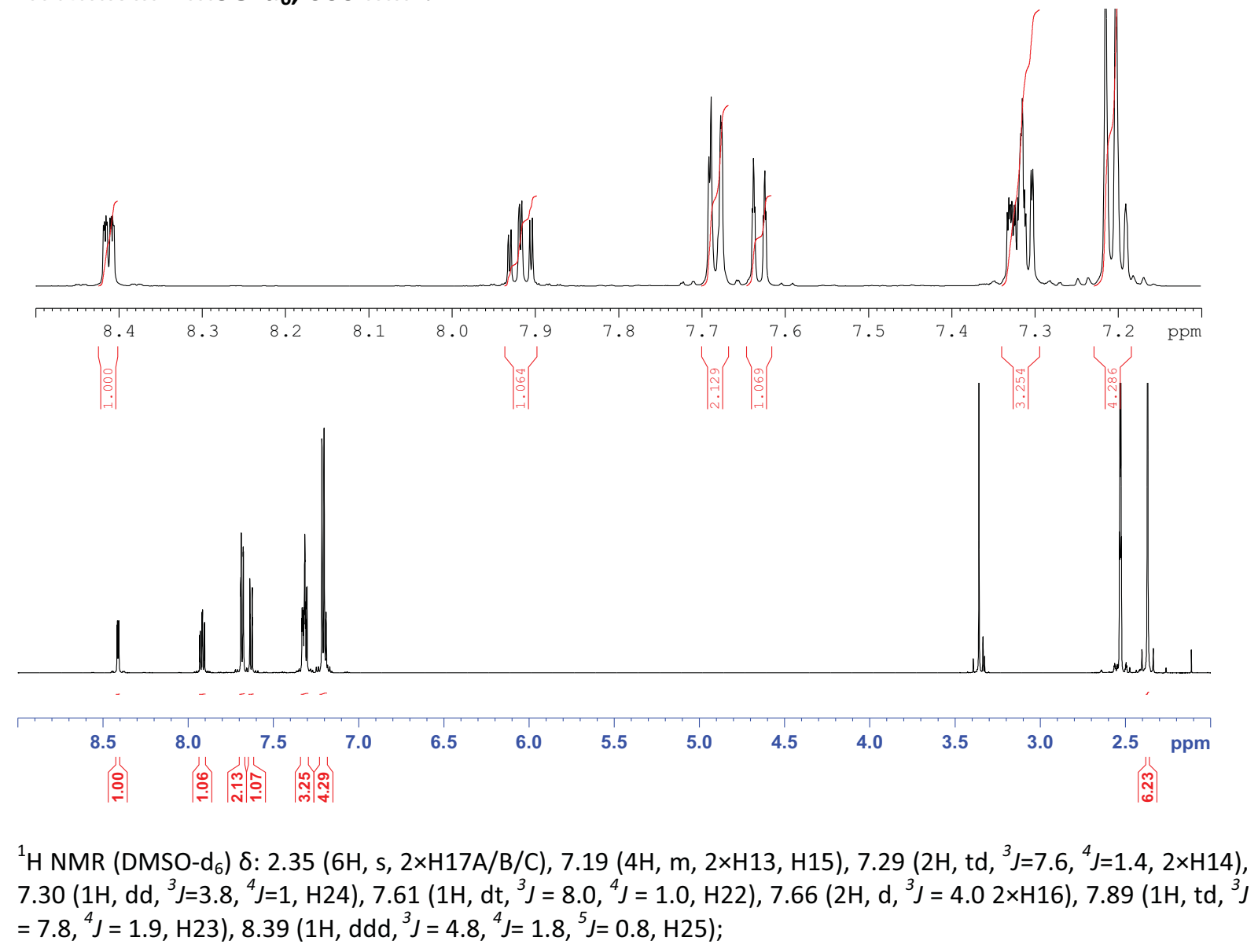


${ }^{1} \mathrm{H}$ NMR in $\mathrm{CDCl}_{3}, 600 \mathrm{Mhz}$ :

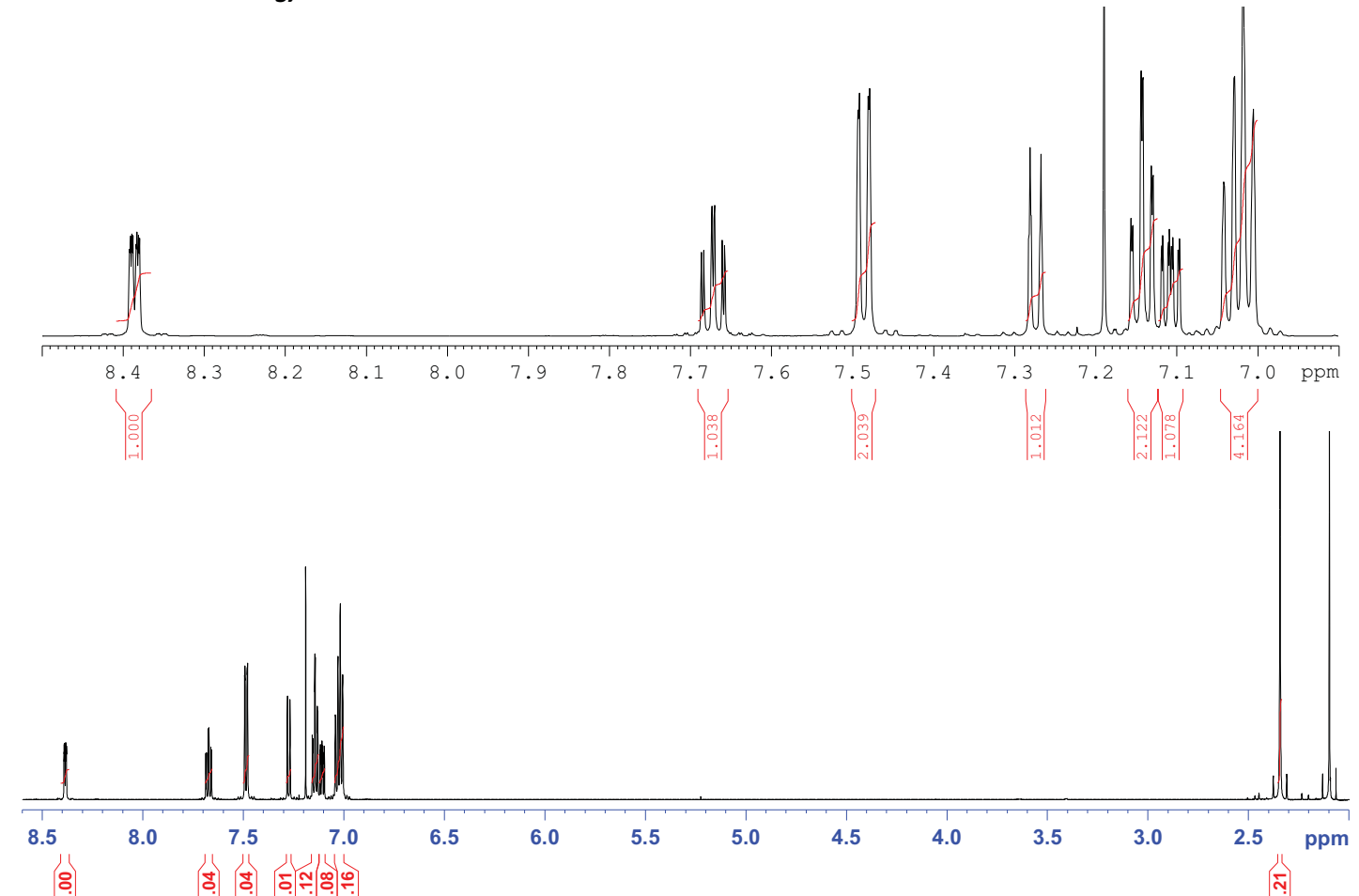

${ }^{1} \mathrm{H} \mathrm{NMR}\left(\mathrm{CDCl}_{3}\right) \delta: 2.34(6 \mathrm{H}, \mathrm{s}, 2 \times \mathrm{H} 17 \mathrm{~A} / \mathrm{B} / \mathrm{C}), 7.02(4 \mathrm{H}, \mathrm{m}, 2 \times \mathrm{H} 13, \mathrm{H} 15), 7.11\left(1 \mathrm{H}, \mathrm{ddd},{ }^{3} \mathrm{~J}=7.6,{ }^{4} \mathrm{~J}=4.9,{ }^{4} \mathrm{~J}=0.9\right.$, $\mathrm{H} 24), 7.14\left(2 \mathrm{H}, \mathrm{td},{ }^{3} \mathrm{~J}=7.6,{ }^{4} \mathrm{~J}=1.3,2 \times \mathrm{H} 14\right), 7.27\left(1 \mathrm{H}, \mathrm{dt},{ }^{3} \mathrm{~J}=8.0,{ }^{4} \mathrm{~J}=0.9, \mathrm{H} 22\right), 7.49\left(2 \mathrm{H}, \mathrm{dd},{ }^{3} \mathrm{~J}=7.7,{ }^{4} \mathrm{~J}=1.2\right.$, 2×H16), $7.67\left(1 \mathrm{H}, \mathrm{td},{ }^{3} J=7.7,{ }^{4} \mathrm{~J}=1.9, \mathrm{H} 23\right), 8.39\left(1 \mathrm{H}, \mathrm{ddd},{ }^{3} \mathrm{~J}=4.9,{ }^{4} \mathrm{~J}=1.9,{ }^{5} \mathrm{~J}=0.8, \mathrm{H} 25\right)$;

${ }^{13}$ C NMR in DMSO-d 6,600 Mhz:

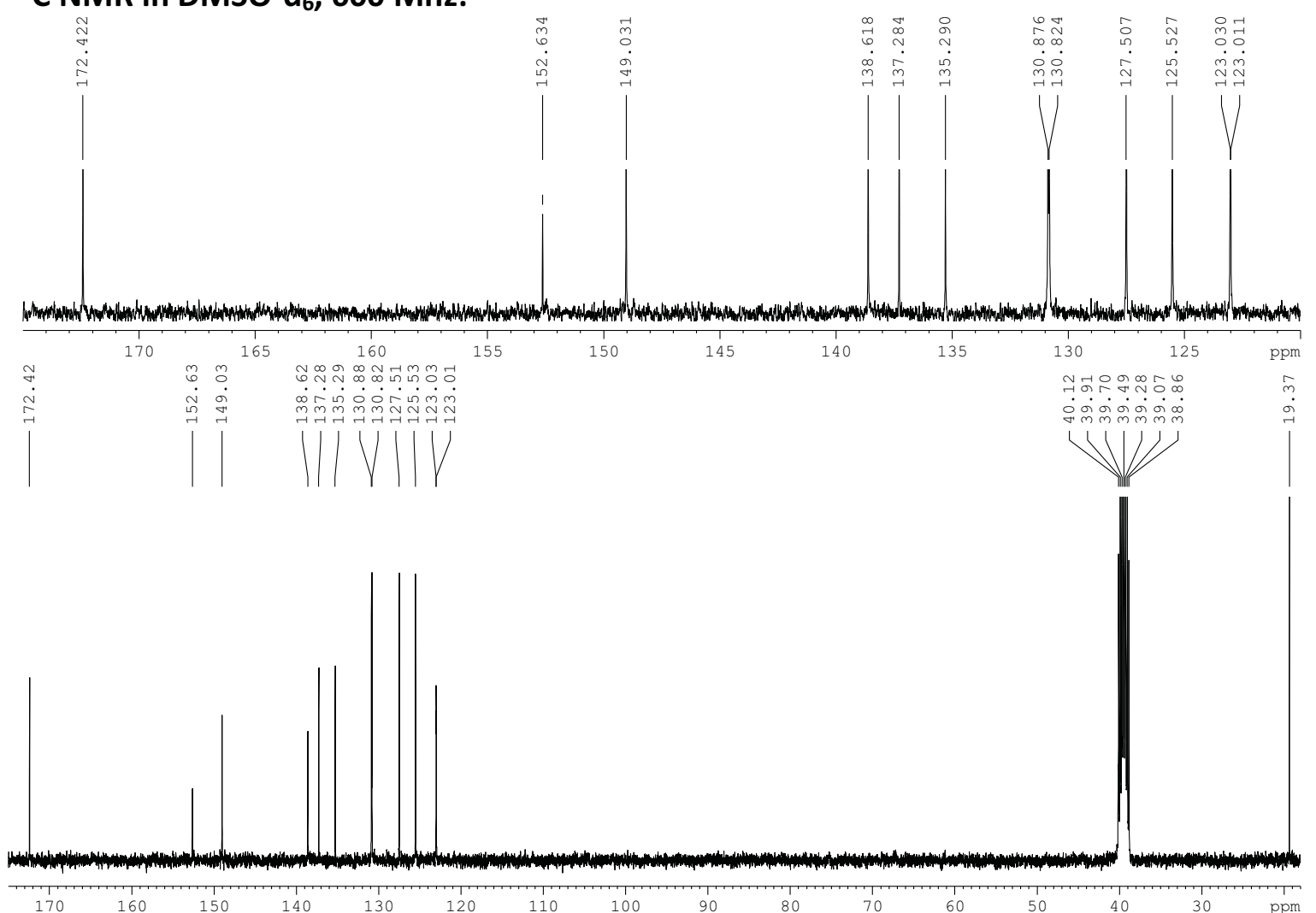

${ }^{13}$ C NMR (DMSO-d $d_{6}$ ) $\delta: 19.37,123.03,125.53,127.50,130.82,130.88,135.29,137.29,138.61,140.03,149.03$, $152.63,172.42$. 


\section{FT-IR ( $\mathrm{KBr}$ disc):}

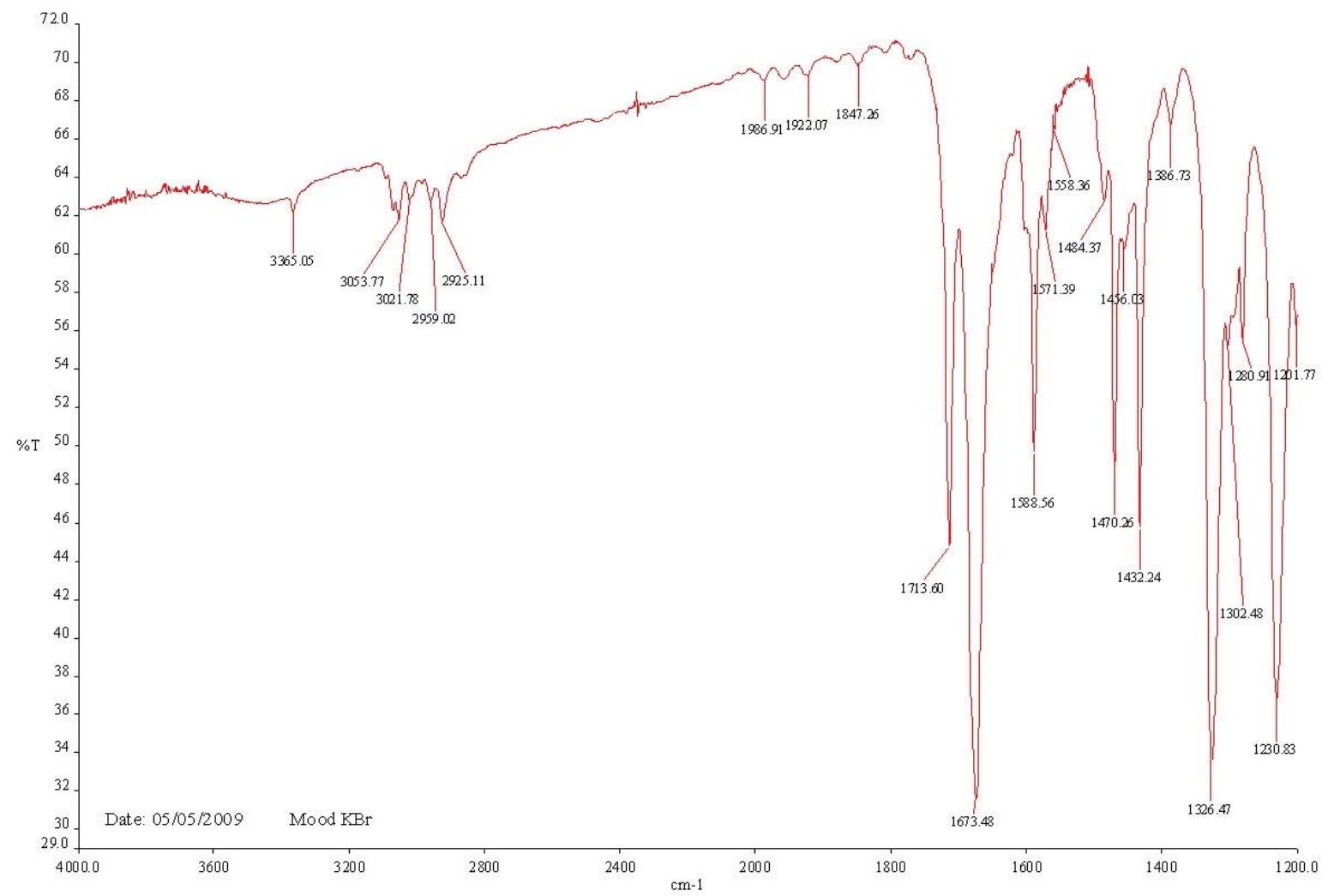

IR (KBr disc): 3365 (w), 3054 (w), 3021 (w), 2959 (w), 2925 (w), 1714 (s), 1673 (s), 1588 (s), $1571(w), 1484(w)$, $1470(s), 1456(w), 1432(s)$; 
Supplementary Table 1 on crystal packing and interactions:

Statistics on actual contacts (\%) in the Mxod crystal packings.

\begin{tabular}{|c|cccc|}
\hline Mmod & $\mathrm{H}$ & $\mathrm{C}$ & $\mathrm{N}$ & $\mathrm{O}$ \\
\hline $\mathrm{H}$ & 23.9 & & & \\
$\mathrm{C}$ & 48.0 & 8.7 & & \\
$\mathrm{~N}$ & 3.3 & 0.2 & 0.2 & \\
$\mathrm{O}$ & 15.7 & 0.0 & 0.0 & 0.0 \\
\hline Mpod & $\mathrm{H}$ & $\mathrm{C}$ & $\mathrm{N}$ & $\mathrm{O}$ \\
\hline $\mathrm{H}$ & 20.4 & & & \\
$\mathrm{C}$ & 51.8 & 7.6 & & \\
$\mathrm{~N}$ & 5.1 & 0.1 & 0.0 & \\
$\mathrm{O}$ & 13.4 & 1.7 & 0.0 & 0.0 \\
\hline Mood & $\mathrm{H}$ & $\mathrm{C}$ & $\mathrm{N}$ & $\mathrm{O}$ \\
\hline $\mathrm{H}$ & 30.1 & & & \\
$\mathrm{C}$ & 40.6 & 8.3 & & \\
$\mathrm{~N}$ & 4.3 & 0.3 & 0.0 & \\
$\mathrm{O}$ & 14.5 & 1.9 & 0.0 & 0.0 \\
\hline
\end{tabular}




\section{Overlay of the Mxod molecular structure pairs.}

In the pairs of overlaid structures from the Mxod series below the main transoid-imide conformation is seen as noted previously in all four of the tennimide macrocycles conformations.[6-8] For the trezimide structures there is an approximation of the cisoidarrangement of $\mathrm{O}=\mathrm{C} \bullet \bullet \mathrm{C}=\mathrm{O}$ for one of the three imide groups especially in the pyrimidinebased structures.

Mpod (navy blue) and Mmod (red) molecular structures.

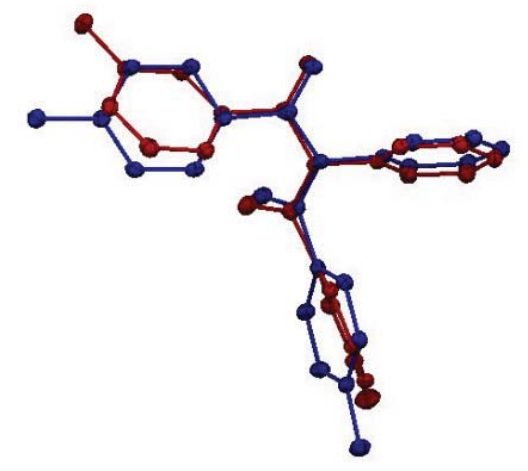

Mpod (grey) and Mood (navy blue) molecular structures.

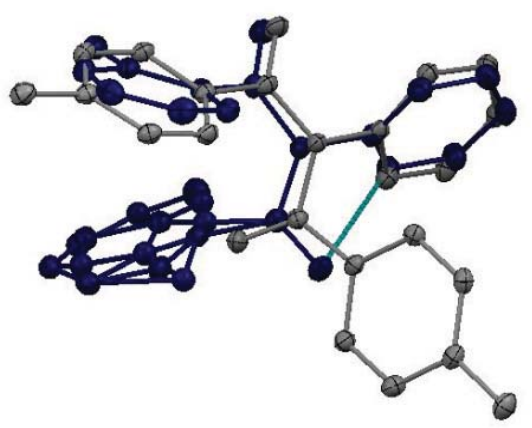

Mmod (grey) and Mood (red) molecular structures.

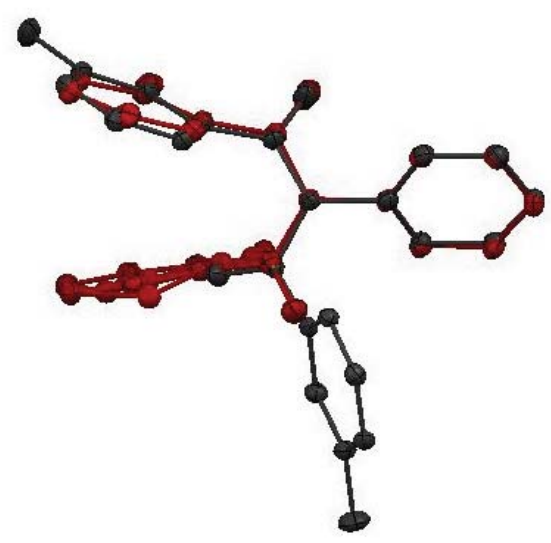


Supplementary Table 2: Comparison of selected torsion/dihedral angles in Mxod (IV)-(VI) ( $\AA$, ०).

\begin{tabular}{|c|c|c|c|c|c|}
\hline Structure & (Mpod) & (Mmod) & $(\text { Mood })^{a}$ & DOKXOR & SOLSUI ${ }^{b}$ \\
\hline \multicolumn{6}{|l|}{ Torsion angles } \\
\hline N1-C1-C11-C16 & $31.0(2)$ & 39.83(19) & $47.7(3)$ & $-26.1(3)$ & $\begin{array}{l}141.7(2) \\
-152.0(2)\end{array}$ \\
\hline N1-C2-C31-C36 & $15.8(2)$ & 49.21(18) & $-122.5(3)$ & $-17.6(3)$ & $\begin{array}{l}-44.8(3) \\
54.4(3)\end{array}$ \\
\hline $\mathrm{O} 1=\mathrm{C} 1-\mathrm{N} 1-\mathrm{C} 2$ & $-154.70(15)$ & $-134.50(15)$ & $-147.2(2)$ & $138.7(2)$ & $\begin{array}{l}150.7(2) \\
-147.0(2)\end{array}$ \\
\hline $\mathrm{O} 1=\mathrm{C} 1-\mathrm{C} 11-\mathrm{C} 12$ & $30.1(2)$ & $37.7(2)$ & $50.3(4)$ & $-27.9(3)$ & $\begin{array}{l}137.7(2) \\
-135.7(2)\end{array}$ \\
\hline $\mathrm{O} 2=\mathrm{C} 2-\mathrm{N} 1-\mathrm{C} 1$ & $33.7(2)$ & $10.8(2)$ & $-158.7(2)$ & $-11.0(3)$ & $\begin{array}{l}-23.5(3) \\
14.6(3)\end{array}$ \\
\hline $\mathrm{O} 2=\mathrm{C} 2-\mathrm{C} 31-\mathrm{C} 32$ & $14.7(2)$ & $47.5(2)$ & $-120.0(3)$ & $-15.4(3)$ & $\begin{array}{l}-40.7(3) \\
51.8(3)\end{array}$ \\
\hline C11-C1-N1-C2 & $29.2(2)$ & 51.12(18) & $39.4(3)$ & $-45.3(3)$ & $\begin{array}{l}-31.0(3) \\
37.8(3)\end{array}$ \\
\hline C11-C1-N1-C21 & $-173.99(14)$ & $-152.92(12)$ & $-148.0(2)$ & $166.5(2)$ & $\begin{array}{l}169.5(2) \\
-154.2(2)\end{array}$ \\
\hline C31-C2-N1-C1 & $-143.62(14)$ & $-167.09(12)$ & $22.4(3)$ & $167.1(2)$ & $\begin{array}{l}153.5(2) \\
-162.9(2)\end{array}$ \\
\hline C31-C2-N1-C21 & 59.05(18) & $37.40(18)$ & $-150.3(2)$ & $-45.5(3)$ & $\begin{array}{l}-46.8(3) \\
29.5(3)\end{array}$ \\
\hline \multicolumn{6}{|l|}{$\begin{array}{l}\text { Interplanar } \\
\text { angles }\end{array}$} \\
\hline $\mathrm{C}_{6} / \mathrm{C}_{5} \mathrm{~N}$ & $89.44(6)$ & $62.44(5)$ & $56.44(9)$ & 74.31(7) & $\begin{array}{l}78.40(8) \\
74.73(7)\end{array}$ \\
\hline $\mathrm{C}_{6} / \mathrm{C}_{5} \mathrm{~N}$ & $80.33(5)$ & $67.51(5)$ & 51.81(9) & $70.70(6)$ & $\begin{array}{l}77.09(7) \\
66.89(7)\end{array}$ \\
\hline $\mathrm{C}_{6} / \mathrm{C}_{6}$ & $75.22(5)$ & 59.19(5) & $26.89(13)$ & $76.07(8)$ & $\begin{array}{l}83.49(6) \\
59.88(6)\end{array}$ \\
\hline \multicolumn{6}{|c|}{$\begin{array}{l}\text { Notes: } \\
\text { (a) Major conformation details for Mood (VI) only (at C31A). } \\
\text { (b) DOKXOR and SOLSUI are the related 3-fluoro and 2-fluoro derivatives, respectively. }\end{array}$} \\
\hline
\end{tabular}


Central Imide Group Interplanar angles and deviations from planar geometry (for atoms).

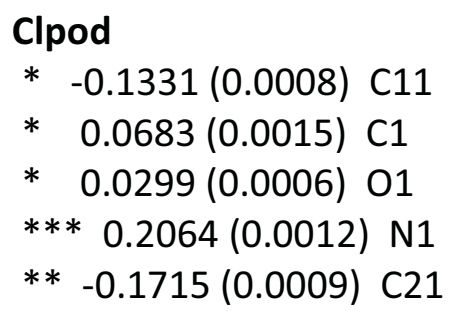

Angle to previous plane (with approximate esd) $=40.86(7)^{\circ}$

* $-0.0482(0.0006)$ C31

* $-0.0377(0.0014) \mathrm{C} 2$

* $0.1842(0.0009) 02$

$* * *-0.3516(0.0012) \mathrm{N} 1$

** $0.2533(0.0008)$ C21

\section{Clmod}

* $0.0914(0.0007) \mathrm{C} 11$

* $-0.0493(0.0013) \mathrm{C} 1$

* $-0.0241(0.0005) 01$

$* * *-0.1325(0.0009) \mathrm{N} 1$

** 0.1145 (0.0007) C21

Angle to previous plane (with approximate esd) $=35.50(7)^{\circ}$

* $-0.0466(0.0005)$ C31

* $-0.0423(0.0012) \mathrm{C} 2$

* $0.1905(0.0007) 02$

$* * *-0.3592(0.0010) \mathrm{N} 1$

** 0.2575 (0.0007) C21

\section{Clood}

* $0.0949(0.0007)$ C11

* $-0.0367(0.0013) \mathrm{C} 1$

* $-0.0308(0.0005) 01$

$* * *-0.1540(0.0010) \mathrm{N} 1$

** 0.1265 (0.0008) C21

Angle to previous plane (with approximate esd) $=24.73(8)^{\circ}$

* $0.0417(0.0004)$ C31

* $0.0151(0.0013) \mathrm{C} 2$

* $-0.1044(0.0008) 02$

$* * * 0.1847(0.0010) \mathrm{N} 1$

** $-0.1371(0.0007)$ C21 


\section{Mpod}

* $0.0329(0.0008)$ C11

* $-0.0294(0.0014) \mathrm{C} 1$

* $-0.0024(0.0005) 01$

* $-0.0369(0.0010) \mathrm{N} 1$

* $0.0358(0.0008)$ C21

Angle to previous plane (with approximate esd) $=41.56(6)^{\circ}$

* $-0.0311(0.0006)$ C31

* $-0.0482(0.0013) \mathrm{C} 2$

* $0.2155(0.0008) 02$

*** $-0.4644(0.0011) \mathrm{N} 1$

** $0.3283(0.0008)$ C21

\section{Mmod}

* $-0.1379(0.0007)$ C11

* $0.0735(0.0013) \mathrm{C} 1$

* $0.0286(0.0005) 01$

$* * * 0.2119(0.0009) \mathrm{N} 1$

** -0.1761 (0.0007) C21

Angle to previous plane (with approximate esd) $=38.46(6)^{\circ}$

* $-0.0500(0.0004)$ C31

* $-0.0311(0.0012) \mathrm{C} 2$

* $0.1609(0.0007) \mathrm{O} 2$

$* * *-0.2957(0.0010) \mathrm{N} 1$

** $0.2159(0.0007) \mathrm{C} 21$

\section{Mood}

* $-0.1572(0.0012) \mathrm{C} 11$

* $0.0850(0.0021) \mathrm{C} 1$

* $0.0255(0.0009) 01$

$* * * 0.2505(0.0017) \mathrm{N} 1$

** -0.2038 (0.0012) C21

Angle to previous plane (with approximate esd) $=36.52(11)^{\circ}$

* $0.1416(0.0011)$ C31A

* $-0.0557(0.0021) \mathrm{C2}$

* $-0.0341(0.0009) 02$

$* * *-0.2462(0.0016) \mathrm{N} 1$

** $0.1945(0.0012)$ C21 